\title{
Bridging Bio-Nano Science and Cancer Nanomedicine
}

Mattias Björnmalm, ${ }^{1, *}$ Kristofer J. Thurecht, ${ }^{2}$ Michael Michael, ${ }^{3,4}$ Andrew M. Scottt, 5 and Frank Caruso ${ }^{1, *}$

${ }^{1}$ ARC Centre of Excellence in Convergent Bio-Nano Science and Technology, and the Department of Chemical and Biomolecular Engineering, The University of Melbourne, Parkville, Victoria 3010, Australia

${ }^{2} \mathrm{ARC}$ Centre of Excellence in Convergent Bio-Nano Science and Technology, The Australian Institute for Bioengineering and Nanotechnology and The Centre for Advanced Imaging, The University of Queensland, Brisbane, Queensland 4072, Australia

${ }^{3}$ Division of Cancer Medicine, Peter MacCallum Cancer Centre, Melbourne, Victoria 3000, Australia

${ }^{4}$ The Peter MacCallum Department of Oncology, The University of Melbourne, Parkville, Victoria 3010, Australia

${ }^{5}$ Olivia Newton-John Cancer Research Institute, and School of Cancer Medicine, La Trobe University, Melbourne, Victoria 3084, Australia

${ }^{6}$ Department of Molecular Imaging and Therapy, Austin Hospital, Heidelberg, Victoria 3084, Australia 


\begin{abstract}
The interface of bio-nano science and cancer medicine is an area experiencing much progress, but also beset with controversy. Core concepts of the field-e.g., the enhanced permeability and retention (EPR) effect, tumor targeting and accumulation, and even the purpose of "nano" in cancer medicine - are hotly debated. In parallel, considerable advances in neighboring fields are occurring rapidly, including the recent progress of "immuno-oncology" and the fundamental impact it is having on our understanding and the clinical treatment of the group of diseases collectively known as cancer. Herein, we: (i) revisit how cancer is commonly treated in the clinic and how this relates to nanomedicine; (ii) examine the ongoing debate on the relevance of the EPR effect and tumor targeting; (iii) highlight ways to improve the next-generation of nanomedicines; and (iv) discuss the emerging concept of working with (and not against) biology. While discussing these controversies, challenges, emerging concepts, and opportunities we explore new directions for the field of cancer nanomedicine.
\end{abstract}


Our continuously improving ability to engineer nanomaterials with tailored properties has provided a strong foundation for applications across a range of biomedical settings. ${ }^{1,2}$ To date, a diverse set of engineered nanomaterials have been developed, including both inorganic (e.g., gold, ${ }^{3}$ iron oxide,,${ }^{4}$ silver, ${ }^{4}$ and silica or silicon $\left.{ }^{5}\right)$ and organic nanoparticles (e.g., lipid-based, ${ }^{6}$ templated, ${ }^{7}$ cell-membrane derived, ${ }^{8}$ and layer-bylayer assembled ${ }^{9,10}$ ). These developments have led to rapidly growing interest in the area of nanomedicine, which leverages the strengths of nanoscience and nanotechnology to achieve improved patient outcomes. ${ }^{11-}$ ${ }^{13}$ For the purposes of this article we focus on approaches using the type of engineered nanomaterials listed above and consider biologics (such as antibodies) a separate entity.

Cancer nanomedicine is the application of nanomedicine to the treatment of cancer, and while the field has seen enormous progress in recent years (especially academically) there is still much to achieve. ${ }^{14-}$ ${ }^{17}$ Key concepts in the field, including the enhanced permeability and retention (EPR) effect, tumor targeting and accumulation, as well as the role of "nano" in cancer medicine, are all subjects of ongoing debate; ${ }^{18-20}$ a debate that is a cornerstone to the concepts discussed in this article.

Herein, we provide an overview of the field of cancer nanomedicine, and discuss controversies and challenges, and emerging concepts and opportunities (Figure 1). We recently discussed strategies for accelerating the field of bio-nano science, ${ }^{13}$ and our focus in this article is on the ongoing debates and controversies associated with key concepts in cancer nanomedicine. Our intention is to provide an overview accessible to the wide range of researchers active in the area (e.g., chemists, biologists, oncologists, engineers, material scientists), with a special focus on exploring opportunities and new directions for the field. We start by revisiting the standard treatment of cancer to provide background for the subsequent discussions on the concept of "tumor targeting", and emerging concepts in the development of the nextgeneration of cancer nanomedicines. 
CANCER NANOMEDICINE

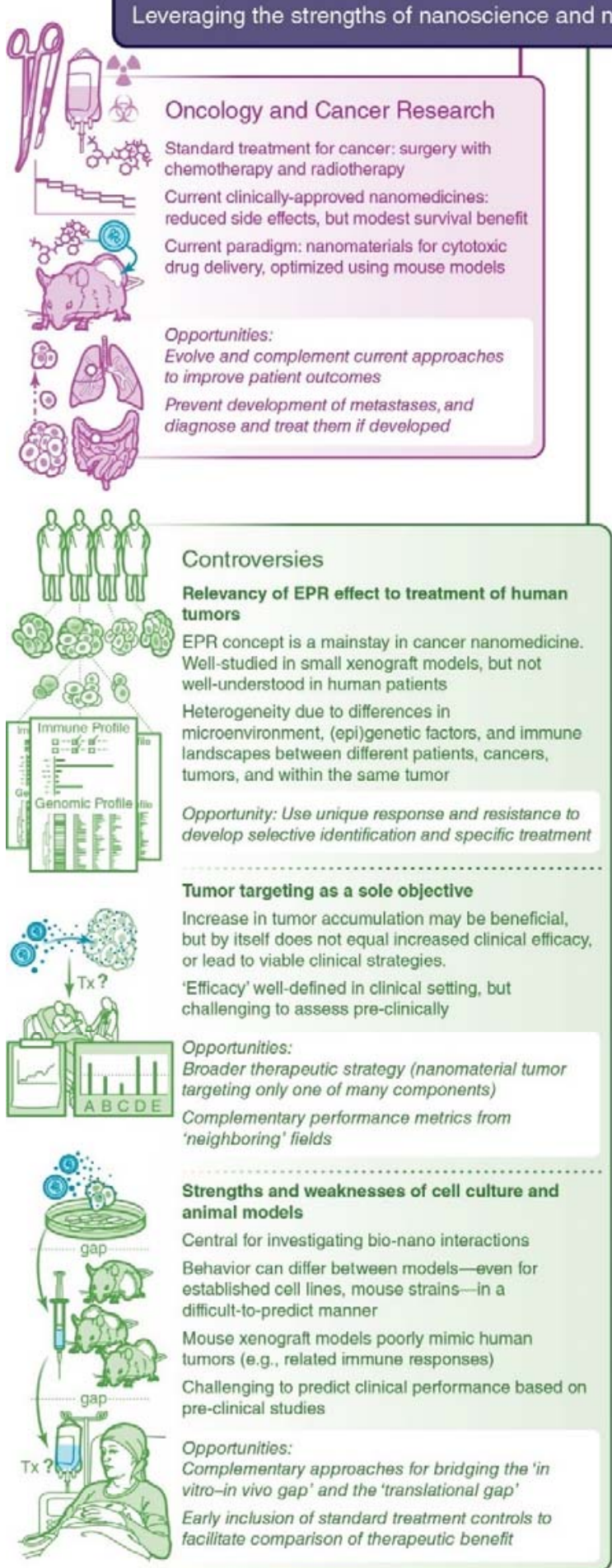

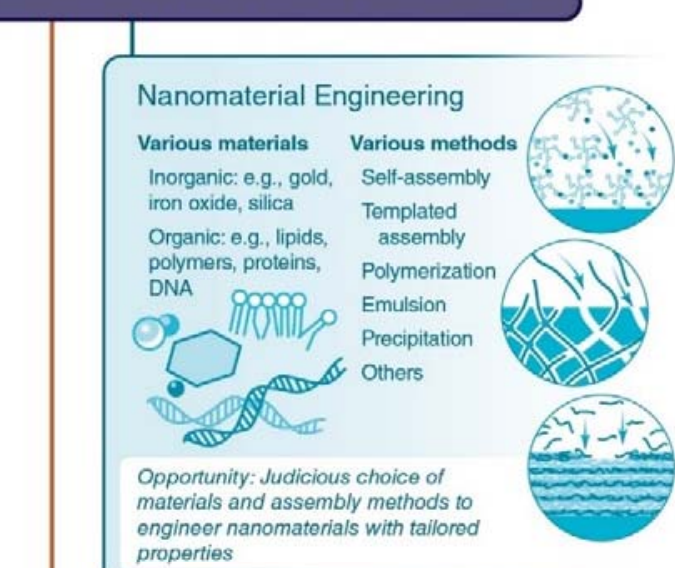

properties
Emerging concepts and opportunities for next-generation nanomedicine development

New methods and assays:

In vitro: e.g. bioprinted 3D models, microfluidics, tumor spheroids, explants

In vivo: e.g., immunocompetent animal models with spontaneous tumors, metastasis, and tumor immunity; canine cancer patients

New objectives and philosophies: 'Disease-first' vs, 'formulation-first' approach 'Simplicity' (e.g., easy, robust, reliable, reproducible) vs 'complexity' (e.g., advanced, intricate, delicate, difficult)

Working with biology (not against it)

- Leverage biological setting (e.g., tumor

pre-conditioning, multistage systems), instead of trying to 'overcome' it - Interact with immune system to induce and sustain anti-turnor responses, instead of trying to 'hide' from it

Standardization of study conduct and reporting

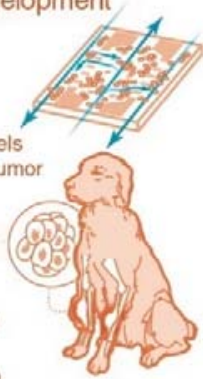

\section{Fields with integration potential:}

Immuno-oncology (cancer

immunotherapy): nanomaterials uniquely suited for enhancing immune

system-based approaches to treat cancer

Theranostics: using nanomaterials

facilitating patient stratification, treatment evaluation, dose adjustment, regulatory decision-making

Comparative oncology as a translational drug development strategy

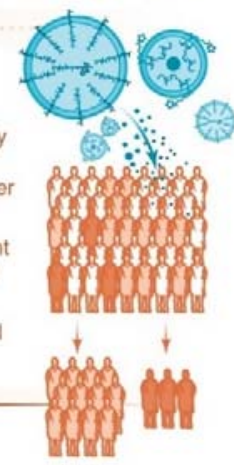

EPR, enhanced permeability and retention

Figure 1. Overview of current challenges and opportunities in field of cancer nanomedicine, at the intersection of oncology, cancer research, chemistry, materials science and nanomaterial engineering. 


\section{Standard treatment in the clinic}

Cancer is a highly heterogeneous and multifaceted disease. The treatment approach is divided into curative or non-curative therapy, subject to the extent of disease and the general clinical state of the patient. ${ }^{21-24}$ Determination of the extent of disease ("staging") can involve both imaging as well as direct visualization strategies (e.g., endoscopy or visualization at time of surgery). In the curative ("radical") setting the aim is to remove all of the tumor either by surgery or by surgery combined with radio- and chemotherapy (Figure 2). These well-established treatment options can cure many primary tumors (tumor at the site where cancer developed), but the vast majority of cancer-related deaths are instead due to metastatic tumors (tumors forming after cancer cells migrate from a primary tumor into other tissues and locations in the body). ${ }^{25}$ Where a curative approach is not feasible, the focus is on improvements in overall survival and quality of life; for example through chemotherapy and targeted therapy (e.g., with molecular targeted agents and antibodies). Metastatic disease is therefore an attractive target for the development of new treatments that aim to provide substantial patient survival benefit. ${ }^{26}$

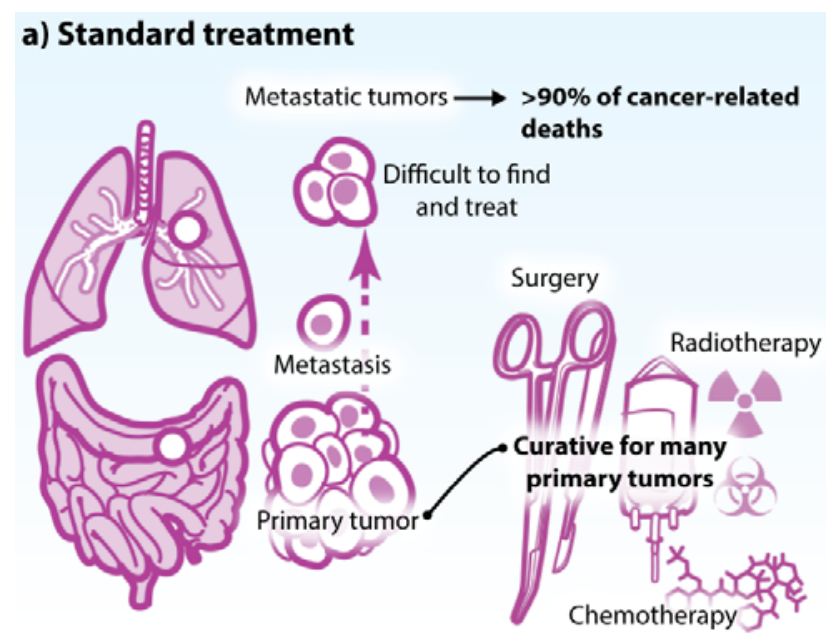

\section{b) Cancer nanomedicine in the clinic}
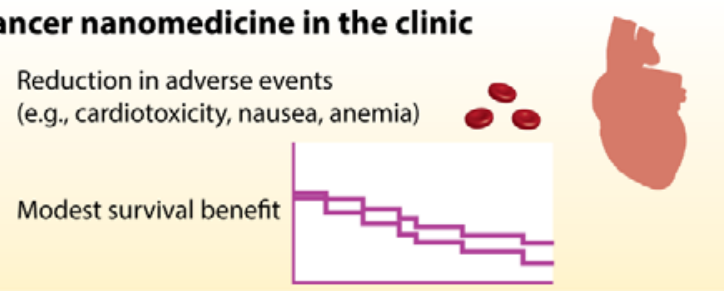
Figure 2. a) Current cancer treatment typically involves surgery combined with chemotherapy and radiotherapy. This is curative for many primary tumors. However, metastasis (cancer cells that migrate from the primary site and establish secondary tumors in other tissues) remains difficult to treat and causes most cancer-related deaths. b) Cancer nanomedicines that are being used in the clinic today are primarily used for their capacity to reduce side effects, as the survival benefit is often modest. ${ }^{27}$

To date, thousands of cancer nanomedicines have been developed, with around a dozen approved for clinical use. ${ }^{14,15}$ For most of these, the main benefit is the reduction of adverse events: e.g., decreased nausea/vomiting, hair loss, anemia and cardiotoxicity (Figure $\mathbf{2 b}$ ). ${ }^{28}$ While some recent clinical trials are showing promise, ${ }^{18}$ the survival benefit afforded by using nanomedicines compared to standard treatment is typically low. ${ }^{28}$ For example, in a recent meta-analysis comparison of liposomal versus conventional nonliposomal chemotherapy ( 14 clinical trials, 2589 patients in total) no increase in survival was found. ${ }^{27}$ These results are in stark contrast to preclinical mouse studies where significantly increased survival was observed. ${ }^{27}$ Reasons for this discrepancy include differences between human and mouse tumor microenvironments, dosing regimens, bioavailability, pharmacokinetics and pharmacodynamics, as well as a lack of standardization in the conduct and reporting of preclinical anticancer efficacy studies. Importantly, while many of the drug delivery systems included in these clinical trials were developed many years ago, the fundamental concepts and rationale underpinning much of the field of cancer nanomedicine have remained largely unchanged. For example, the approach of using nanomaterials to directly kill tumors through cytotoxic drug delivery optimized using mouse models. Moving forward, we should consider how we can evolve and complement current approaches to both increase our fundamental understanding of the behavior of nanomaterials in cancer nanomedicine, and to facilitate translation into improved patient outcomes. 


\section{EPR controversy}

Human tumors are highly complex and heterogeneous, with differences observed from patient to patient, between multiple tumors in the same patient (e.g., primary tumor and metastasis, and between metastases), and even within the same tumor microenvironment (Figure 3). ${ }^{29-32}$ This has important implications for the response to therapies and for the development of resistance. ${ }^{33}$ Nevertheless, there are several hallmarks that cancers have in common, including sustained proliferation and growth, changes in the behavior of the immune system, and the induction of angiogenesis (i.e., formation of new blood vessels). ${ }^{34,35}$

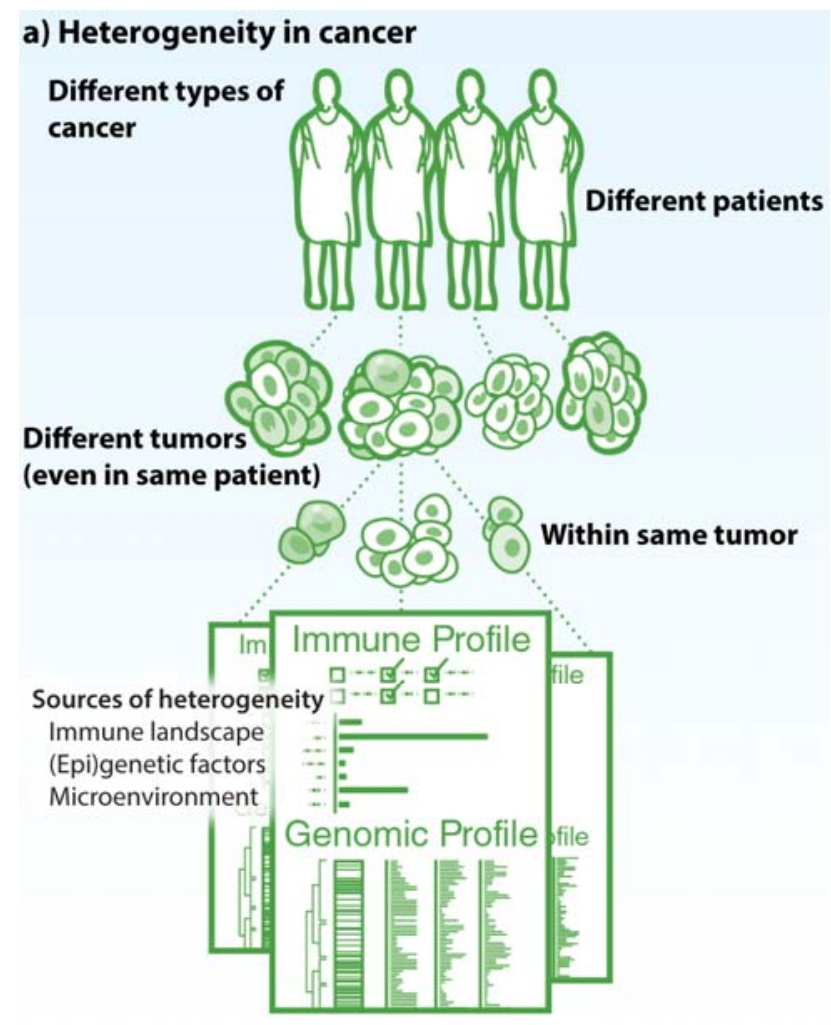

\section{b) Magnitude of EPR effect varies}

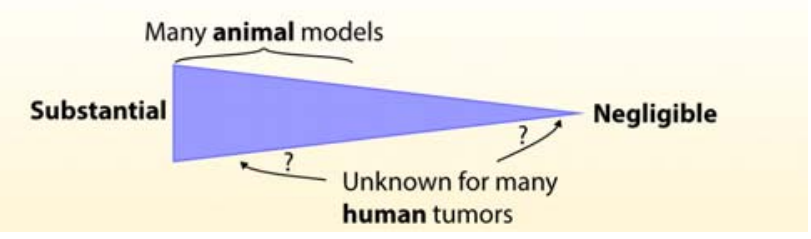

Figure 3. a) Tumors have distinct features that can change with the type of cancer, the patient, the type of tumor, and even within the tumor. b) The existence and magnitude of an EPR effect for a tumor is governed 
by all of the factors listed in (a). Some of these factors are well-established for transplanted tumors in small animal models, but remain largely unknown for many human cancers.

The abnormal tissue environment associated with cancer raises both challenges and opportunities for the development of treatments. Challenges include vascular and interstitial barriers for the delivery of therapeutics to tumors, ${ }^{36}$ which has important implications for tumor penetration of anticancer drugs, ${ }^{37}$ antibodies, ${ }^{38}$ and nanomedicines. ${ }^{28,39}$ On the other hand, unique features associated with tumors poses opportunities, as they may enable selective identification and treatment.

It has been known since the late 1950s that dyes injected into the blood of mice and rats (bearing implanted tumors) or cats and dogs (with spontaneous tumors) can extravasate out of the blood stream and accumulate in tumors. ${ }^{40-42}$ In 1986, two independent studies showed that: (i) tumor vessels are typically more permeable to large molecules than many normal vessels (studied using rabbits with transplanted tumors ${ }^{43}$ ), and (ii) that some tumors can retain and accumulate large molecules due to reduced clearance (studied using mice with transplanted tumors ${ }^{44}$ ). These studies formed the foundation to what is known as the "enhanced permeability and retention" (EPR) effect.

Since these original studies, the EPR effect has become a mainstay of much of cancer nanomedicine. While it has been well-studied in the case of small animal models with transplanted tumors, its relevancy to human tumors remains controversial. ${ }^{45-49}$ Recent examples highlighting this controversy include statements such as the "EPR effect fails in the clinic" and "works in rodents but not in humans", 50 while others assert that the "EPR effect is the main mechanism of tumor penetration by nanocarriers and is a clinically relevant phenomenon". ${ }^{1}$

Much of the current knowledge on the EPR effect in patients and human tumors is based on early, relatively low-resolution imaging (both spatial and temporal) using radiolabeled lipid vesicles. ${ }^{52-56}$ While 
patient biopsies have further shown that nanomaterials can preferentially accumulate in human tumors ${ }^{57}$ the extent to which the EPR effect varies between different patients and tumor types remains to be explored, and therefore its relevance to the clinical use of cancer nanomedicines remains uncertain (Figure 3b). It is noteworthy that the first clinically approved nano-sized anticancer drug carrier-Doxil/Caelyx-was approved for treatment of Kaposi's sarcoma, ${ }^{58}$ a cancer of the endothelial cells of blood and lymph vessels which makes endothelial barriers highly permeable, so that even red blood cells can leak out. ${ }^{45,58}$ For this cancer, Doxil/Caelyx (pegylated-liposomal doxorubicin) was found to be clinically more effective and less toxic than the standard combination chemotherapy (doxorubicin, bleomycin, and vincristine) ${ }^{59}$ For other, less leaky tumors, such as many breast cancers, Doxil was not as effective, but it did reduce side-effects (e.g., cardiotoxicity) and is currently used for that reason. ${ }^{60}$ (Additional examples and more extensive discussion on this topic are available elsewhere ${ }^{45}$ ). The varying efficacies reported for these examples across different cancers and patient groups further highlight the complexities and heterogeneities associated with clinically relevant tumors. A recent study ${ }^{61}$ using pet dogs (companion animals with cancers that developed spontaneously), in what is known as "comparative oncology", ${ }^{62,63}$ provides further evidence to the heterogeneity of the EPR effect. For the seven dogs that had carcinomas (a cancer of epithelial tissues), six (ca. 85\%) displayed high uptake levels of liposomes, as determined using high resolution imaging. However, only one of the four dogs (25\%) that had sarcomas (a cancer of soft tissues) displayed signs of liposome retention. Similar results have been observed in clinical studies. ${ }^{64}$ Taken together, while the EPR effect can be strong in some tumors, it can also be negligible in others, and should therefore not be considered a general feature of all cancers and tumors. Emerging hybrid imaging techniques such as simultaneous positron emission tomography-magnetic resonance imaging (PET-MRI) ${ }^{65-68}$ may help in expanding our understanding of the EPR effect in human cancers and patient tumors, and its relevance to nanomaterials.

\section{The be-all and end-all of targeting}


One of the core principles of cancer nanomedicine is the concept of using nanoparticles to selectively or specifically accumulate at tumor sites. From a clinical perspective, this "targeting" is only of interest if it leads to increases in efficacy, i.e., improved patient outcomes. But while efficacy is well-defined in the clinical setting (e.g., reduction of adverse events, increase in response rate, and increase in progression-free and overall survival), it is a more fluid concept that can be challenging to assess pre-clinically. This has led to a large focus on "targeting" in and of itself, as it can be easier to assess and try to optimize, for example using rodent models (Figure 4).

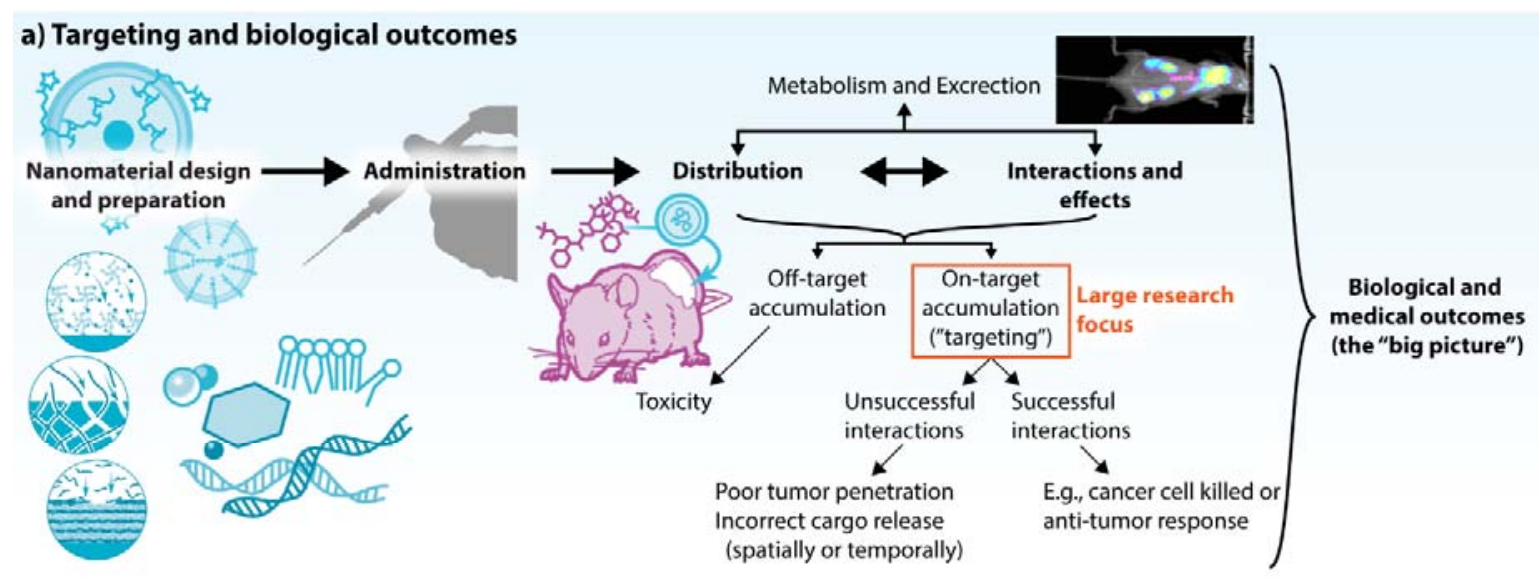

\section{b) Lessons from neighboring fields}
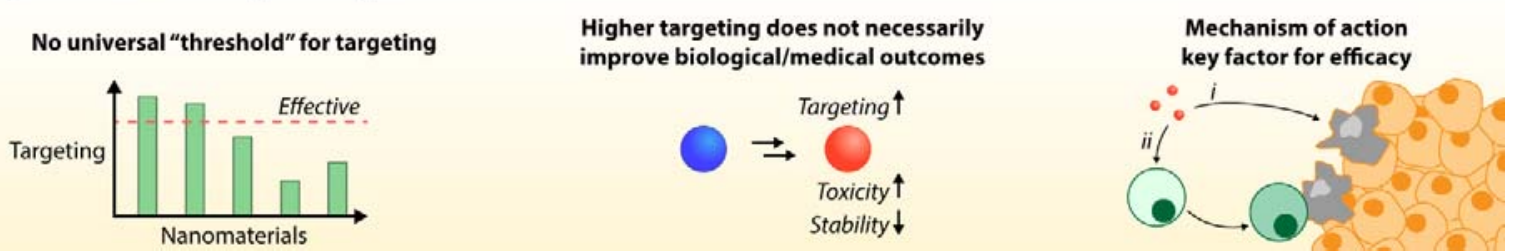

Figure 4. a) The efficacy of nanomaterials for cancer medicine depends on a range of factors, some of which are challenging to assess pre-clinically. Substantial efforts have focused on improving the "targeting" of nanomaterials (e.g., increase in tumor accumulation) and it is important to remember that one factor in isolation only represents a small part of the bigger picture. b) Lessons from neighboring fields (e.g., therapeutic affinity proteins) include that there is no universal "threshold" value for targeting, i.e., at which an ineffective therapeutic becomes effective, and that an increase in targeting does not necessarily improve efficacy. The mechanism of action is also a key factor for therapeutic efficacy. For example, if the target 
cells are cancer cells, or they are other, associated cells (e.g., immune cells); or if the intended molecular target (i.e., site of action) is accessible on the surface of the cell; or if internalization is required. The mouse imaging figure in (a) is adapted with permission ${ }^{69}$ Copyright 2015 American Chemical Society.

While the concept of tumor targeting of nanomaterials has been a controversial topic for many years, ${ }^{70-75}$ a recent meta-analysis ${ }^{76}$ surveyed the literature from the past ten years and found that the amount of injected dose (ID) of particles that accumulated at the tumor was typically less than $1 \%$ (Table 1). This seemingly low number re-energized the debate on whether tumor targeting is a viable concept. ${ }^{77-80}$ While this type of debate can be healthy and constructive for a field as active as cancer nanomedicine, there are some important points to note. First, while an increase in tumor targeting may be of interest scientifically, if it does not lead to improved patient outcomes, then clinically it is not a viable therapeutic strategy. Therefore, care should be taken not to overemphasize the importance of numbers such as percentage of injected dose accumulated at a tumor (Figure 4). Second, similar to what we have discussed previously, ${ }^{13}$ many of the challenges faced in the field of cancer nanomedicine are not unique to the field and there are lessons that can be learnt from neighboring areas of research. For example, much of the work, and terminology, of developing engineered nanomaterials for cancer therapies has roots in the field of targeted anti-cancer therapies using antibodies. 
Table 1. Tumor accumulation of nanomaterials in rodent models. Based on data from online repository introduced by Wilhelm et al. ${ }^{76}$ containing 238 data sets from 118 publications. "Active" and "passive" refers to nanomaterials functionalized and not functionalized with targeting ligands, respectively.

\begin{tabular}{|l|l|l|}
\hline Targeting & $\begin{array}{l}\text { \%ID at tumor, } \\
\text { median (min-max) }\end{array}$ & $\begin{array}{l}\text { \%ID per gram of tumor tissue, } \\
\text { median (min-max) }\end{array}$ \\
\hline Active & $1.00(0.001-18.9)$ & $4.60(0.02-45.8)$ \\
\hline Passive & $0.60(0.0002-14)$ & $2.60(0.01-28.8)$ \\
\hline Data combined & $0.70(0.0002-18.9)$ & $3.17(0.01-45.8)$ \\
\hline
\end{tabular}

Over the last few decades, therapeutic antibodies have revolutionized the treatment of cancer and today form part of the backbone in cancer therapy. ${ }^{81-83}$ To address questions such as "how does the accumulation of nanomaterials compare to other targeted therapies?", it may be informative to compare the accumulation described above for nanomaterials with tumor accumulation values observed for antibodies. In mice, the accumulation of antibodies in "xenografts" (e.g., human cancer cells implanted into mice) can vary greatly, typically between 0.5 to $50 \%$ ID per gram of tumor tissue ${ }^{84}$ In contrast, accumulation of antibodies in human patient tumors is much lower, typically much less than $0.01 \%$ ID per gram of tumor tissue (Table 2).

Table 2. Examples of tumor accumulation of antibodies in human cancer patients.

\begin{tabular}{|l|c|c|c|c|}
\hline Cancer & $\begin{array}{c}\text { Number of } \\
\text { patients }\end{array}$ & $\begin{array}{c}\text { Days since antibody } \\
\text { administered }\end{array}$ & $\begin{array}{c}\text { Accumulation of antibody } \\
\text { (\% administered dose / g tumor) }\end{array}$ & Reference \\
\hline Lymphoma & 10 & 2 & $0.0002-0.009$ & 85 \\
\hline Leukemia & 1 & 1 & 0.01 & ${ }^{86}$ \\
\hline
\end{tabular}




\begin{tabular}{|l|c|c|c|c|}
\hline Leukemia & 10 & 1 & $0.005-0.011$ & 87 \\
\hline Neuroblastoma & 6 & 1 & $0.08^{\mathrm{a}}$ & 88 \\
\hline Colorectal & 27 & $6-7$ & $0.0002-0.01$ & 90 \\
\hline Colorectal & 12 & 7 & $0.001-0.009$ & 91 \\
\hline Colorectal & 32 & $3-17$ & 0.007 & 92 \\
\hline Colorectal & 4 & $>1$ & $0.002-0.006$ & 93 \\
\hline Ovarian & 2 & 5 & 0.009 & 94 \\
\hline Ovarian & 1 & $>3$ & $0.005-0.01$ & 96 \\
\hline Carcinoma & 7 & $5-7$ & $0.001-0.026$ & 97 \\
\hline Melanoma & 17 & $7-10$ & $0.007-0.0003$ & 98 \\
\hline Melanoma & 6 & $3-4$ & $0.0003-0.006$ & 95 \\
\hline Sarcoma & 14 & $2-3$ & & \\
\hline
\end{tabular}

${ }^{a}$ per $\mathrm{mL}$ tumor

Despite the very low accumulation of antibodies commonly observed in human tumors compared to mouse xenograft models, many antibodies display substantial clinical efficacy, both for the imaging and treatment of cancer. ${ }^{81-84,99-101}$ Therefore, when comparing these metrics of accumulation (Figure 5) it is important to remember that they only capture one aspect of a bigger picture (Figure 4a). Inspired by the success of antibodies, other high affinity proteins for targeted therapies are also being developed. Examples include nanobodies, ${ }^{102}$ antibody fragments, ${ }^{103}$ repeat proteins,,${ }^{104}$ bispecific affinity proteins, ${ }^{105,106}$ and other non-immunoglobulin based protein scaffolds. ${ }^{107}$ For some of these, first-in-human clinical trials have recently been published. ${ }^{108-110}$ A key message from these and similar studies (and the nanomaterialantibody comparison, Figure 5) is that a single parameter (e.g., \%ID accumulated at tumor) forms only a small part of evaluating the performance of targeted therapies, and care should be taken not to overemphasize this aspect when engineering nanomaterials for targeted therapies (Figure 4). 


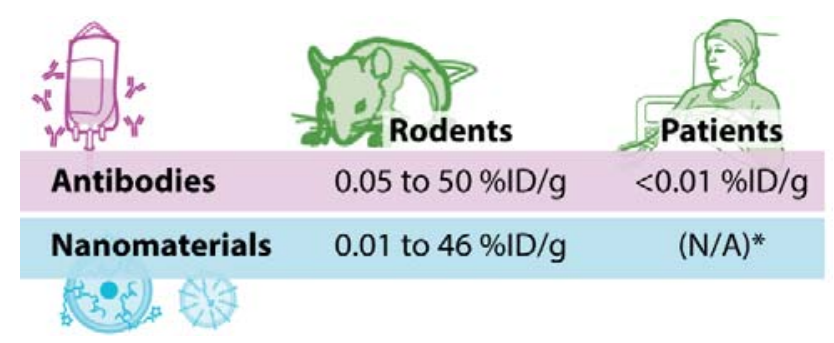

Figure 5. Summary of typical tumor accumulation metrics: 0.01 to $45.8 \% \mathrm{ID} / \mathrm{g}$ for nanomaterials in rodents (Table 1), 0.5 to $50 \% \mathrm{ID} / \mathrm{g}$ for antibodies in rodents, ${ }^{84}$ and typically much less than $0.01 \% \mathrm{ID} / \mathrm{g}$ for antibodies in patients (Table 2). *Larger scale, quantitative and systematic studies of tumor accumulation of different nanomaterials in various human tumors are yet to be conducted.

There is growing interest in using antibodies and antibody-like molecules for generating antibodydrug conjugates ${ }^{111,112}$ and for functionalizing nanomaterials. ${ }^{113-116}$ When the tumor accumulation (in animal models) for a wide range of nanomaterials with and without targeting moieties are compared, an increase is observed but a large overlap also exists between the two groups (Table 1, compare "active" and "passive"). Several studies on direct head-to-head comparisons have demonstrated that the functionalization of nanomaterials with targeting moieties does not always increase tumor accumulation, but it often improves cellular uptake. ${ }^{117-122}$ That is, even if the total amount of nanomaterial deposited in a tumor does not increase with the use of a targeting moiety, for the fraction of nanomaterial deposited in the tumor, a targeting moiety can facilitate internalization into the tumor cells. However, antibodyfunctionalization and efficient accumulation does not always lead to efficient internalization, as this depends on the receptor targeted and potentially other, receptor-independent mechanisms involved. ${ }^{123,124}$ Additionally, an increase in internalization efficiency does not necessarily translate into increased activity, due to processes such as endocytic recycling ${ }^{125,126}$ and the mechanism of action of the therapeutic, which may require endosomal release/escape and further translocation (e.g., into the nucleus). ${ }^{1,127,128}$ All of these mechanisms are further complicated by the presence of dynamic biomolecular coronas on nanomaterials in 
biological environments. ${ }^{129}$ These endogenous molecules (e.g., lipids and proteins) can interact with offtarget receptors, possibly inducing difficult-to-predict off-target effects and toxicity. ${ }^{130}$

In addition to functionalizing nanomaterials with targeting ligands, it has also been shown that the tumor accumulation (and more generally, biodistribution and pharmacokinetics) in small animal xenograft models for both functionalized and non-functionalized nanomaterials strongly depends on time after administration of particles, ${ }^{131,132}$ the dose administered, ${ }^{133}$ the diameter of the particles, ${ }^{134}$ and the amount of targeting molecules attached to each particle. ${ }^{135,136}$ The strategy used to attach targeting ligands onto nanomaterials is also important, with recent data indicating that for some methods only $\sim 4 \%$ of attached targeting ligands have a favorable orientation for recognition by their target receptor, which can lead to poor (and heterogeneous) outcomes. ${ }^{137}$ The addition of targeting ligands may also impose a "binding site barrier" effect, which retards or even prevents tumor penetration of therapeutics into tumor tissues due to strong interactions of targeting ligands with cells in the periphery of tumors. ${ }^{138-141}$ This "binding site barrier" is only one of many obstacles tumor-targeted nanomaterials encounter inside the body, and is an additional factor that must be considered when trying to elucidate mechanisms that drive the efficacy of nanomedicines.

\section{Strengths and weaknesses of animal models}

When nanomaterials are administered in vivo, they interact with the physiological environment (be it in a mouse or a human) at multiple levels: the sub-cellular and cellular levels, the tissue level, and the organ and organism levels. ${ }^{142,143}$ Depending on the intended application, many of these interactions can be thought of as "barriers" that need to be overcome. ${ }^{144,145}$ When studying these barriers for cancer nanomedicine using mouse xenograft models it is important to consider the substantial differences that exist between different xenograft models and mouse strains. For example, when comparing liposomal tumor accumulation and plasma clearance rates in multiple xenograft mouse models, order-of-magnitude differences have been observed. ${ }^{146,147}$ The age and sex of mice may also affect results, which, if not accounted for, can make 
comparisons difficult. ${ }^{148,149}$ It has also been shown that there are substantial differences between intratumor distribution of liposomes in xenograft mouse models, with macro-accumulation not always reflecting micro-accumulation in specific regions inside tumors. ${ }^{150}$ These results highlight the complexities that exist in xenograft mouse models (even when well-established cell lines and mouse strains are used), complexities that are even more intricate for human patients.

Cell culture studies and small animal models (e.g., mice with xenografts) have been and continue to be essential for the field of nanomedicine, as they are central for the investigation of fundamental bionano interactions. However, while examples of successful correlations between preclinical animal studies and clinical human trials exist, ${ }^{151,152}$ it remains challenging to use these type of models to predict clinical performance. An approach that is being investigated to accelerate discovery, development, and translation of antibodies and antibody-drug conjugates from animal models to the clinic is pharmacokineticpharmacodynamic (PK-PD) modelling. ${ }^{153,154}$ These types of strategies integrate pre-clinical and clinical data, and therefore require judicious choice of the pre-clinical models employed. Thus, it is important to remember what these type of models can and cannot tell us. ${ }^{155-158}$ A relevant quote from a recent commentary ${ }^{155}$ reads: "the reality is that the value of a model depends on what the modeler is trying to accomplish. A good use of human tumor xenograft models would be to support an experimental hypothesis, a bad use would be to present animal data that add little to the value of in vitro data, and an ugly use of tumor xenografts would be to facilitate publication of a manuscript or give a false sense of safety or efficacy."

A key difference between human patient tumors and many of the studies that utilize tumors implanted in mice is their relative size. This introduces challenges in interpretation of data obtained using mouse models, as exemplified by this quote: ${ }^{100}$ "The relative mass of a tumor $(0.1-4.0 \mathrm{~g})$ xenografted into and growing in a nude mouse $(15-30 \mathrm{~g})$ is in the range of $0.3-30 \%$. By contrast, the relative mass of a tumor $(2-10 \mathrm{~g})$ in a patient $(70 \mathrm{~kg})$ is in the range of $0.003-0.01 \%$." For the human patient, a tumor of 
equivalent relative size (to the mouse model) would be the size of a basketball (Figure 6). While it is not impossible for tumors to reach this size, it does not represent the standard clinical situation. Larger, resectable (i.e., can be operated on) tumors are surgically removed in patients so even if a tumor had grown to be large before diagnosis then it would typically be surgically removed or debulked (through surgery or other local therapies) as a first step in treatment. ${ }^{21-24}$ By knowing these details, a simple mathematical model can be used to estimate the likelihood that a nanoparticle encounters the tumor during circulation. ${ }^{142}$ In a xenograft mouse model, with a relatively large tumor (e.g., 10\% of body weight), the likelihood of nanoparticle-tumor encounter reaches $50 \%$ after only 6 seconds. ${ }^{142}$ For a human tumor (e.g., $0.005 \%$ of body weight), this takes over 10 days (Figure $6 \mathrm{~b}$ ). ${ }^{142}$ These numbers do not account for factors such as more variable vascularity, higher interstitial pressure and the more pronounced hypoxia present in many human tumors, all factors that can further increase the differences observed between mouse models and patients. This further highlights some of the challenges of using mouse tumor models for predicting nanomaterial performance in the clinic.

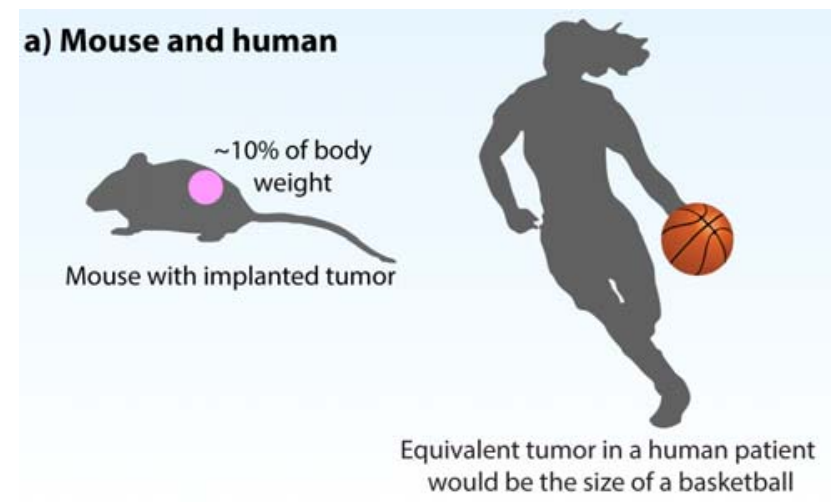

b) Time before nanomaterial encounters tumor
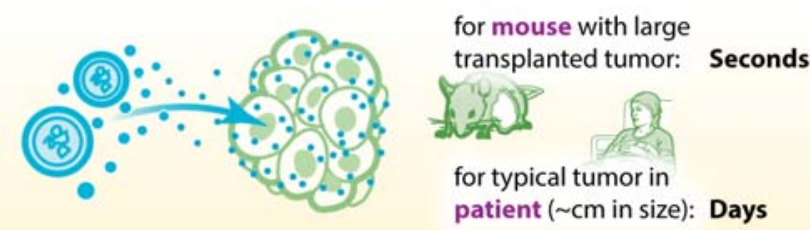

Figure 6. a) While rodent models are well-suited for investigating fundamental bio-nano interactions, it is important to remember that substantial differences exist between xenograft tumors and human tumors. In 
addition to the difference in size, rodent models also typically have compromised immune systems. b) Based on these differences the typical time from administration to nanomaterial-tumor encounter can be estimated using a simple mathematical model. ${ }^{142}$

Despite the explosive growth of cancer nanomedicine, there are many publications today that follow a similar pattern: nanomaterial synthesis, in vitro cell culture, and in vivo mouse xenograft studies. This pattern is so common that it has been identified as an issue by researchers and journal editors, ${ }^{159}$ as it can be difficult to appreciate exactly what the new knowledge and insights are for studies following this pattern. Suggestions to improve this situation include careful consideration of study design and models used. If comparative therapeutic benefit is being investigated, then "standard treatment" controls should be included and compared against (as is standard procedure in clinical studies). This can, for example, include comparing a new cancer nanomedicine against clinically-used liposomal formulations of cancer drugs. If fundamental bio-nano interactions are being investigated (e.g., biodistribution, function under physiological conditions, interactions with tissues and organs), small animal models are often perfectly suitable. But when the main objective is development of new therapies to be translated into the clinic, then it is important to complement these studies with other approaches that can help bridge the "translational gap" (Figure 7). Examples for more mature nanomaterials include the emerging fields of "comparative oncology" 62,63 and "phase 0 " trials. ${ }^{160}$ 


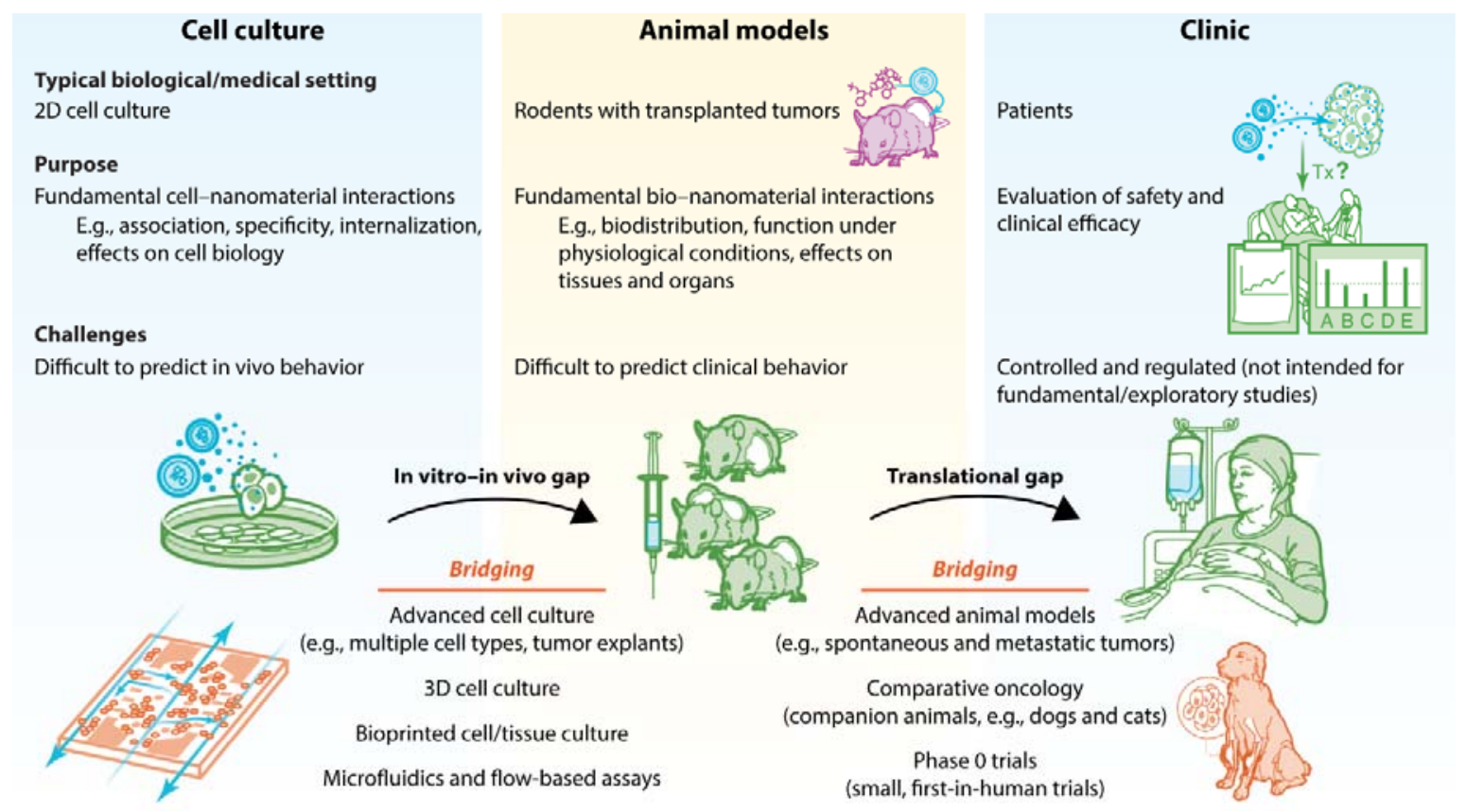

Figure 7. Overview of approaches for developing nanomaterials for cancer nanomedicine. The "in vitroin vivo gap" is the fact that in vitro results can be difficult to translate to in vivo settings. The "translational gap" is the fact that strategies developed with the help of animal models can be difficult to translate to human patients. Example approaches that can facilitate the bridging of these gaps are listed. Specific examples of advanced animal models include syngeneic tumor models (e.g., using immunocompetent mice bearing tumors derived from the same mouse strain), orthotopic tumor models (e.g., colon cancer cells implanted into the colon - i.e., the organ of origin — of mice, instead of subcutaneously), patient-derived tumor xenograft (PDX) models (e.g., using cancerous tissue from patients, instead of cell lines, to establish tumors in mice), and transgenic models (e.g., mice genetically engineered with cancer-causing 'oncogenes', that develop cancers spontaneously).

\section{Developing the next-generation of cancer nanomedicines}

There are several challenges and opportunities associated with the large-scale synthesis, characterization, evaluation, and commercialization of particles that are currently being explored. ${ }^{161-163}$ An important part of these are recent advances in the development of new in vitro and in vivo assays (Figure 7). In vitro, 
engineered 3D tumor models, ${ }^{164,165}$ microfluidic-based assays, ${ }^{166-168}$ the use of tumor spheroids, ${ }^{169,170}$ and the culturing of tumor explants ex vivo are being pursued and have shown promising results. ${ }^{171-174}$ Alternatives that are being explored in vivo include the use of animals and animal models in which tumors develop spontaneously; importantly, these animals typically have an intact immune system, in contrast to the immune-deficient mice commonly used in many xenograft models. Examples include mouse models of advanced spontaneous metastasis, ${ }^{175,176}$ mouse models of tumor immunity, ${ }^{177}$ and canine cancer patients. ${ }^{62,63,178}$ This involves the emerging field of comparative oncology—the study of naturally occurring cancers in companion animals — which has shown promise as a translational development strategy. ${ }^{62,63}$

In parallel with these developments, opportunities exist for improving how these types of studies are conducted and reported. In a meta-analysis ${ }^{179}$ of 74 quantitative, pre-clinical studies, 35 different cell types were used for the xenografts. How tumor accumulation was reported also varied widely, with many studies reporting only normalized accumulation (e.g., \% ID per cubic centimeter or \% $\mathrm{ID}$ per gram of tumor tissue) but not the size or mass of the tissue, making comparisons difficult. An example highlighting this is a study using a mouse model where the accumulation of liposomes was found to depend on the size of the tumor. ${ }^{180}$ For small tumors $(\leq 0.1 \mathrm{~g})$, the accumulation was observed to be around $15 \% \mathrm{ID}$ per gram of tumor tissue, whereas for larger tumors $(\geq 1 \mathrm{~g})$ the uptake was only $3 \%$ ID per gram. ${ }^{180}$ This study used the same type of tumor cell and the same type of liposome, but despite this, when comparing the normalized \%ID per gram of tumor tissue, a 5-fold difference in accumulation was observed. For a study investigating the effect of tumor size on accumulation (as this was ${ }^{180}$ ), this is suitable. But consider if the study instead intended to compare different nanomaterials. If the comparisons are not performed appropriately (e.g., by accounting for differences in tumor size) then the results would be dominated by external effects (in this case, the size of the tumor). Therefore, all of these parameters — both normalized value (e.g., \%ID per gram tumor tissue) and the measurement used to normalize (e.g., tumor mass) need to be reported. To avoid these types of issues, standardization of reporting (and when possible, standardization of experimentation) is 
vital. ${ }^{13,181-184}$ To this end, guidelines and recommendations to facilitate comparison and benchmarking of preclinical studies of nanomedicines have recently been proposed. ${ }^{185}$

Much of the history of nanomaterials for biomedicine, and many of its researchers, have a background in the chemical sciences, and much of the emphasis has therefore been focused on the development of new and exciting nanomaterials (and not on the pathology and biology of the disease). There have been recent calls ${ }^{186}$ for the field to adopt "industry-style frameworks" where strategies for the development of nanomedicines would be focused around the disease and the patient from the outset, instead of on the chemistry and material science: a "disease-first approach" instead of a "formulation-first approach". ${ }^{159}$ While these frameworks are of interest for projects aiming to accelerate clinical translation of nanomedicine, there is also a broader ongoing discussion on the objective and purpose of cancer nanomedicine.

As the field of cancer nanomedicine matures - in parallel with advancements within oncology and cancer biology — the full complexity of the challenge before us has started to emerge. The response of the field towards this complexity can broadly be put into two categories. On the one hand, the seemingly everincreasing complexity of cancer can be met with ever-increasing complexity in material design. An example of this is the recent proposal of a framework based around "nanoproperty integration and synchronization", ${ }^{187}$ which is based around a so-called C-A-P-I-R cascade with 2-R-2-S-P requirements and 3-S transitions, many of which contain difficult balances and trade-offs between conflicting properties such as retention/release, stability/degradation and "stealthy-ness/stickiness". While it is an interesting attempt to combine many of the seemingly conflicting results of the field, it also represents a multidimensional optimization problem for which the solution (when it exists) is most likely different for different cancers, patient groups, and patients, and perhaps even for different tumors in the same patient (e.g., primary or metastasis). ${ }^{29-33}$ On the other hand, this increasing complexity has been met by calls towards simplicity and robustness, ${ }^{188-190}$ for example by focusing translational nanomedicine development 
around combining robust approaches in a stepwise manner. The concept of "minimal design" can be helpful in this pursuit. ${ }^{191}$ Of course, there is rarely a single answer to multifaceted questions, so future research can benefit from pursuing several paths, while keeping the advantages and disadvantages of each in mind.

\section{Using the next-generation of cancer nanomedicines}

The best treatment option for most cancers is based around a combination of several interventions, including well-established options such as surgery, radiation therapy and chemotherapy, ${ }^{21,22}$ often combined with biological therapy: which can include antibody therapy, ${ }^{81-83}$ immunomodulation and $\mathrm{T}$ cell engineering. ${ }^{192,193}$ Nanomedicine can facilitate these approaches, for example by: (i) guiding surgical removal of tumors, ${ }^{194}$ (ii) enhancing radiotherapy, ${ }^{195,196}$ (iii) co-delivering therapeutics to reduce the likelihood of multi-drug resistant cancers developing, ${ }^{197-199}$ and (iv) by stimulating the immune system to induce or sustain anti-tumor responses. ${ }^{200}$

Complementing the approaches outlined above is the possibility of using cancer nanomedicine to stratify patients based on imaging and response. ${ }^{201-203}$ Early work on the imaging of antibodies facilitated their clinical translation and regulatory approval ${ }^{84,100}$ (as knowing where the material is and its ultimate fate facilitates development and regulatory decision making ${ }^{204}$ ) and molecular imaging is today an important tool in drug development and trial design. ${ }^{205,206}$ Imaging techniques are also playing an increasingly important role for nanomedicine. ${ }^{207,208}$ While it is important to remember the costs associated with adding imaging capabilities, ${ }^{209}$ there are ways to reduce these costs. An interesting recent example is the use of "companion particles" with well-established imaging capabilities co-administered with the therapeutic particles. ${ }^{210}$ Another example is using nanomaterials or drugs that are both inherently fluorescent and therapeutic (e.g., cytotoxic), for example quantum $\operatorname{dots}^{211}$ or doxorubicin. ${ }^{212,213}$ Imaging in nanomedicine can help provide feedback on the treatment (“is it working?") as well as help with dose adjustments. This forms the rationale of the field of "theranostics". ${ }^{214-216}$ There have also been recent advances in preparing nanoparticles that can be cleared rapidly and safely (e.g., very small $(<10 \mathrm{~nm})$ nanoparticles), intended for 
tumor therapy and imaging. ${ }^{217,218}$ An example of this is a first-in-human clinical trial of inorganic nanoparticles for the imaging of cancer in patients with metastatic melanoma. ${ }^{219}$ These types of rapidly clearing nanomaterials may facilitate imaging (similar to how small affinity proteins can facilitate imaging compared to larger antibodies ${ }^{108,109}$ ) and may also provide new avenues for drug delivery using carriers that are stable enough that the excess is excreted (e.g., through kidneys and urine) before release of the drug, thus potentially minimizing off-target toxicity.

\section{Working with—and not against—biology}

We have recently proposed a framework centered around "convergent science" towards facilitating the development and translation of materials for biomedical applications that aims to integrate many of the ideas discussed herein. ${ }^{13}$ Recently, an industry/pharma-focused perspective was also published centered around many of these translational challenges. ${ }^{186}$ While there are differences between research focused on translational work and "blue-sky" exploratory work, there is also substantial overlap and lessons that can be learnt. ${ }^{13,186}$ An overarching theme that is emerging in cancer nanomedicine is a shift away from working against biology (overcoming obstacles and barriers), towards working with biology (leveraging and taking advantage of physiology and disease pathologies).

"Working with biology" involves adjustments in both the methodology and objectives of cancer nanomedicine. For example, it has been shown that many drugs have difficulty penetrating more than a few cell diameters away from blood vessels and into extravascular tumor tissue. ${ }^{220}$ Similar problems have been observed with both inorganic and organic particles using mouse models and flow-based in vitro assays. ${ }^{221-}$ ${ }^{225}$ One way to address this challenge is the use of "tumor-penetrating peptides"(Figure 8a). These peptides activate an endocytic transport pathway (the "CendR pathway") related to, but distinct from, macropinocytosis. ${ }^{226}$ This pathway can transport compounds and nanoparticles both directly from cell to cell and "through" cells (i.e., be taken up on one side and released on the other) in a process that is faster 
than diffusion. ${ }^{226}$ Tumor-penetrating peptides can either be conjugated to or co-administered with the nanomaterial. ${ }^{227-229}$

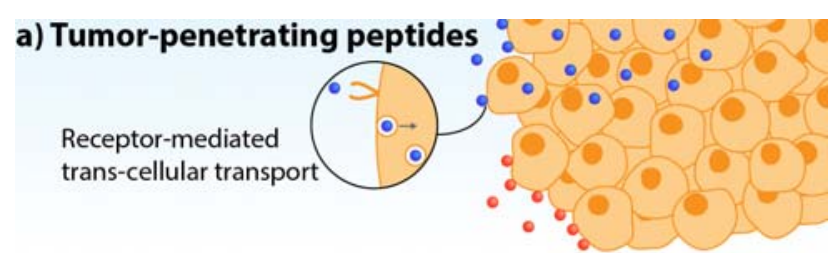

b) Tumor preconditioning

Reduction of tumor cells and ECM

Blood vessel normalization

c) Multi-stage systems

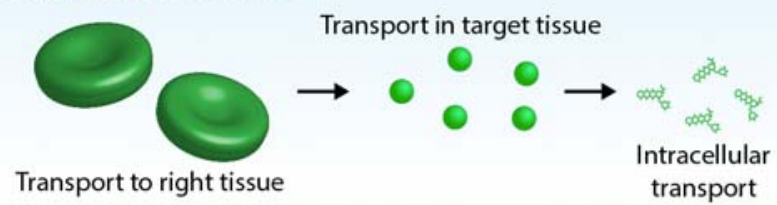

d) Cancer immunotherapy

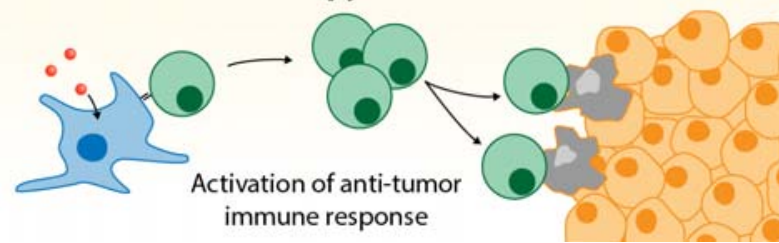

Figure 8. Examples of the concept of "working with biology". a) Using peptides (blue particles) to hitchhike on trans-cellular transport pathways. Red particles illustrate control particles without peptide that get stuck at the periphery. b) Adjusting the biological environment (e.g., through blood vessel normalization) to facilitate anti-tumor drugs and immune cells to reach and distribute within the tumor. c) Multi-stage nanomaterial systems that change depending on the biological setting. For example, blood cellmimicking microparticles with favorable circulation characteristics (transport to tissue) that break into nanoparticles with favorable tissue transport characteristics (transport within tissue) and release a drug that is easily taken up by cells (intracellular transport). d) Using nanomaterials to activate or sustain anti-tumor immune responses. 
A different approach, focused instead on adapting the biological environment, is "tumor preconditioning" (Figure 8b). For example, alleviation of interstitial fluid pressure can be accomplished by reducing the number of tumor cells and the tumor-associated extracellular matrix, as well as through blood vessel normalization; these strategies have all shown promise for increasing nanomaterial penetration and retention (reviewed elsewhere ${ }^{230}$ ). These types of approaches are especially important for difficult-totreat cancers, such as pancreatic cancer. ${ }^{231}$ A related concept is to instead leverage features of the cancerrelated microenvironment, ${ }^{232}$ for example by targeting tumor-associated macrophages, ${ }^{233-236}$ using neutrophils for cell-mediated delivery of liposomal anticancer drugs, ${ }^{237}$ or using particles to assemble drugdepots in the tumor microenvironment. ${ }^{238}$ In a recent study, ${ }^{239}$ it was demonstrated that local tumor irradiation of tumor-bearing mice increased the accumulation of tumor-associated macrophages and enhanced "vascular bursting", which in some cases lead to a sixfold increase in nanoparticle accumulation in the tumor via a cascade of changes to the tumor vasculature and microenvironment.

Multi-stage systems form the basis for a strategy in which multiple components are combined and where each component is intended for different parts of the process, from administration to tumor treatment. ${ }^{240}$ One way to achieve this is the "pre-targeting approach". ${ }^{241}$ In tumor pre-targeting, the targeting component and the effector component are administered sequentially. For example, long-circulating tumortargeting antibodies are first administered and sufficient time is allowed for unbound excess of antibodies to clear. Subsequently, a rapidly clearing effector component (e.g., nanoparticle with an imaging component or drug) with specific, complementary functionality to the antibody can then be administered ${ }^{242}$ Rapid clearance (e.g., through kidneys into urine) can decrease non-specific tissue accumulation and thus improve imaging and reduce toxicity. ${ }^{241}$

A different approach to multi-stage systems involve "particle generators" and "particle clusters". ${ }^{24-245}$ In these types of systems, smaller components with favorable tumor penetration and distribution characteristics (e.g., nanoparticles or molecules that easily diffuse), can be combined into larger structures 
and assemblies with favorable vascular transport characteristics (e.g., microparticles mimicking bloodcirculating platelets) (Figure 8c). ${ }^{243-245}$ These types of structures may also provide new ways to address the challenge of low drug-loading of nanomaterials, a common challenge for the applications of nanomaterials in chemotherapy. ${ }^{246}$ Most of these approaches discussed above (Figure 8a-c) represent subtle shifts in concepts and reasoning where aspects of the biological setting are being leveraged to facilitate improved cancer nanomedicines, but the core principle of drug delivery of cytotoxic drugs to tumors remains largely the same. But there are also new concepts emerging that are fundamentally different to this principle, involving approaches for which particle-based systems may be uniquely suited, such as cancer immunotherapy (Figure 8d).

\section{Cancer immunotherapy and nanomedicine}

In the rapidly developing field of immuno-oncology, strategies for activating and stimulating the immune system to treat cancers are being explored. The core idea is to interact with the immune system in constructive ways to induce and sustain anti-tumor responses.

Cancer cells are different to normal cells in several fundamental ways. ${ }^{34,35}$ These changes give rise to "tumor-specific antigens" that the immune system can use to distinguish cancer cells from non-cancer cells. ${ }^{247}$ However, it has been shown that in some patients with progressive disease tumors and tumorspecific immune cells coexist. ${ }^{248}$ This demonstrates that the induction of an immune response is insufficient to fully prevent disease progression; there are additional ways the tumor prevents effective attacks by the immune system. ${ }^{248-250}$

"Immune checkpoints" are inhibitory pathways that are a natural part of the immune system and whose purpose is to help distinguish between "self" and "foreign", to modulate the duration and amplitude of an ongoing immune response, and to ensure elimination of any threat with minimal damage to healthy cells and tissues. ${ }^{251}$ In the last few years, there have been substantial clinical advances in the field of cancer 
treatment using "immunotherapies" that target immune checkpoints and similar pathways, providing new opportunities for nanomedicine. For example, several high-profile clinical studies have recently been published demonstrating the strong clinical potential of strategies utilizing "immune checkpoint blockades" (reviewed elsewhere ${ }^{252}$ ) that use antibodies to block parts of these inhibitory pathways, thus enabling the immune system to attack previously resistant tumors. Although immuno-oncology (also known as cancer immunotherapy) approaches are being used clinically, and have led to improved patient outcomes, a proportion of patients respond poorly. ${ }^{253-256}$ Therefore, it remains a challenge to constructively interact with and activate the immune system for a broader range of patients and types of cancers. This is a challenge that nanomedicines may be uniquely suited for, as many types of nanomaterials are inherently capable of interacting with (and enhancing the function of) key immune cells and organs..$^{257,258}$

Nanomedicine systems are in the size range of viruses and bacteria (dimensions of nanometers to micrometers), and the human body has evolved intricate mechanisms to identify, inactivate, and remove or destroy foreign objects of this size..$^{259}$ Consequently, much of the work in cancer nanomedicine has been focused on "hiding" from the immune system (e.g., to limit the induction of immune responses and to reduce the sequestration of nanomaterials) which, due to the effectiveness and robustness of the vast array of defense mechanisms that exists in the human body, has proven to be an uphill battle. Therefore, a shift away from "hiding from the immune system" towards instead enabling constructive interactions with it, represents a fundamental change in the rationale and design of nanomedicine systems (Figure 9). 


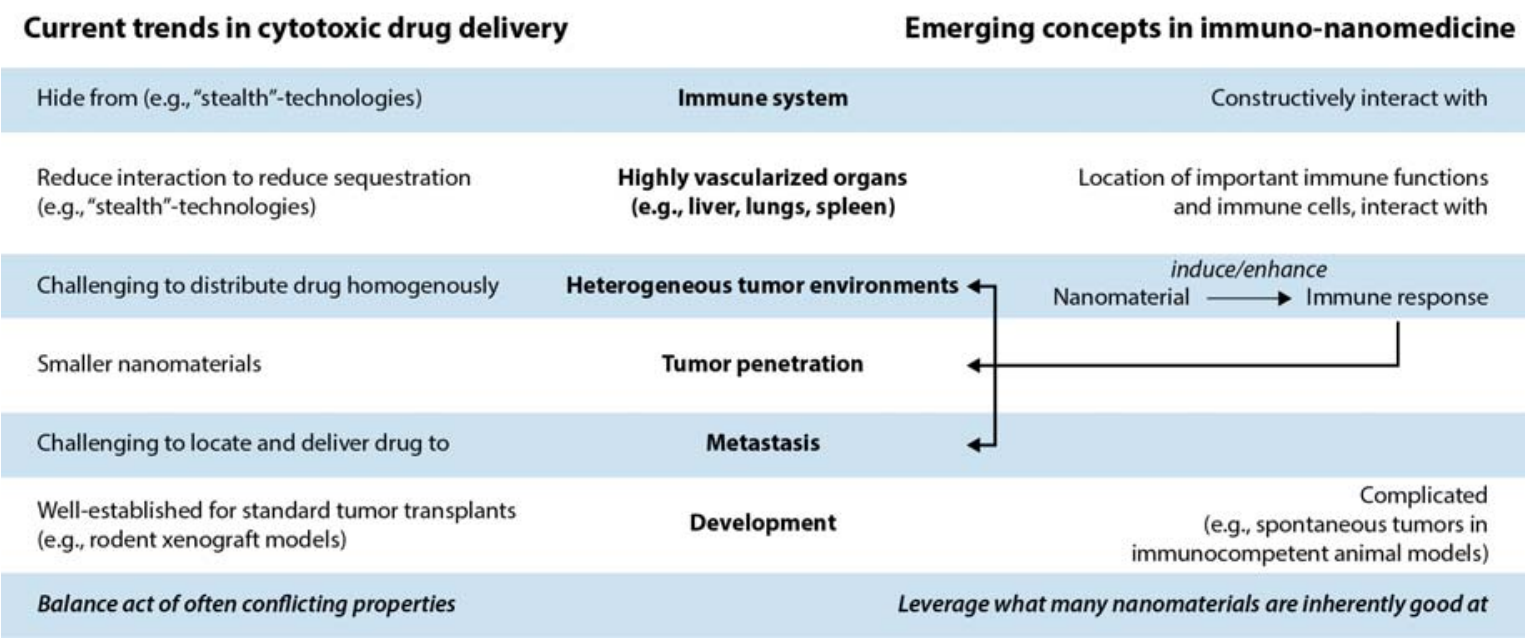

Figure 9. Comparison of the current paradigm of cytotoxic drug delivery to tumors with emerging trends in using nanomaterials for cancer immunotherapy. A key distinction is that the target is no longer killing tumors directly, but instead to interact constructively with the immune system.

We recently published a review article outlining immunological principles for the rational design of particles, ${ }^{260}$ and review articles from the last few years outlining how particle systems can be used to combine nanomedicine with immuno-oncology also exist. ${ }^{261-266}$ In the following we will highlight recent developments and insights in the emerging field of "immune-nanomedicine" for the treatment of cancer.

The core of combining nanomedicines with immuno-oncology is to leverage what many nanomaterials are intrinsically good at (e.g., interacting with phagocytic cells and the reticuloendothelial or mononuclear phagocyte system ${ }^{267}$ ), instead of trying to engineer nanomaterials that can hide from the immune system. For example, both soft and hard nanomaterials have been shown to be capable of accumulating in lymph nodes and lymphoid tissues, and to strongly interact with different types of immune cells (e.g., dendritic cells, B cells, and T cells) to induce controlled immune responses. ${ }^{268-271}$ 
Circulating nanomaterials tend to strongly interact with the liver and the spleen (e.g., Kupffer cells, hepatic B cells, and splenic macrophages). ${ }^{272,273}$ While much work has focused on reducing this very efficient sequestration of circulating nanomaterials, there is also potential to leverage this capability for inducing and modulating immune responses. For example, Kupffer cells form an important part of the innate immune response and have been shown to have important roles in the prevention of the formation of liver metastases, and could facilitate and enhance the sequestration of circulating tumor cells. ${ }^{274,275}$

With these notable features in mind, nanomaterial-based approaches have the potential to be transformative for activating and enhancing anti-tumor immune responses. Examples include the activation of pre-existing tumor-specific immune cells, or through the delivery of tumor-associated antigens to antigen-presenting cells to mount new immune responses. ${ }^{276-279}$ One example of this is using antigencapturing particles to improve the effect of radiotherapy administered with immunotherapy, through the "abscopal effect". ${ }^{280}$ Another example is the recent translation into clinical trials of a lipid nanoparticle that targets dendritic cells to induce anti-tumor immune responses. ${ }^{281} \mathrm{~A}$ related recent example is the use of nanoparticles for reprogramming circulating immune cells (i.e., in situ) into having tumor-recognizing capabilities. $^{282}$

More fundamentally, the immune system is in constant balance between immunosuppressive and immunostimulatory compounds and interactions, and nanomedicine-based approaches can help shift this balance towards enhanced anti-tumor responses while maintaining tolerance towards healthy tissues (Figure 10). A strategy for achieving this include the spatiotemporally controlled delivery of immunomodulatory compounds to lymphoid tissues and/or the tumor site. ${ }^{283-288}$ Particles can also be attached to cells ex vivo and then administered as particle-cell constructs, which can improve the efficacy of vaccination, ${ }^{289}$ and enhance the activity of administered T cells in "adoptive cell therapy" approaches. ${ }^{290}$ Particles have also been functionalized with multiple antibodies for combinatorial immunotherapy, which showed increased effectiveness compared to administration of soluble antibodies by themselves. ${ }^{291}$ 


\section{a) Immunomodulation}

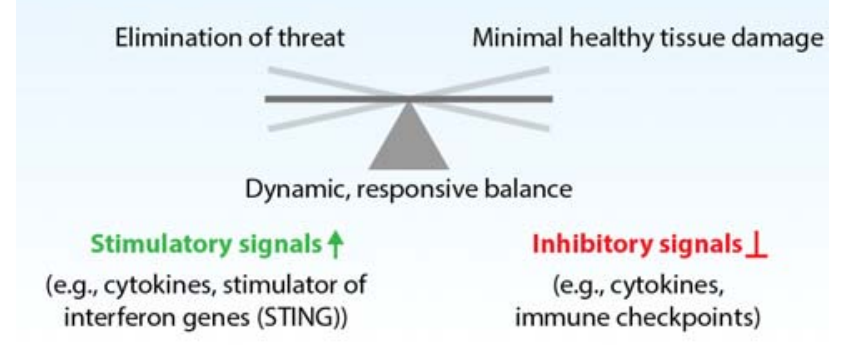

\section{b) Emerging cancer immunotherapies}

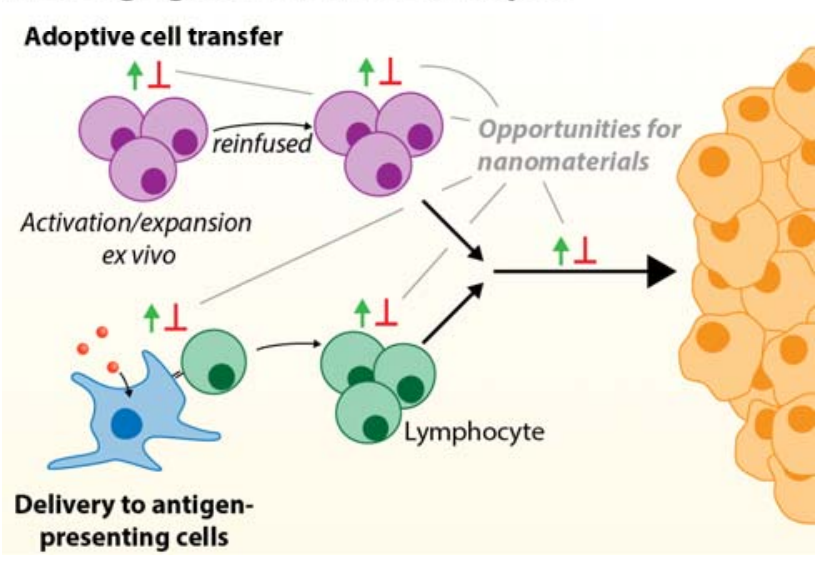

Figure 10. a) The immune system is in a constant balance between stimulatory and inhibitory signals that for healthy individuals assures that any threats (e.g., infections) are eradicated with minimal side effects. In cancer, this balance is upset (e.g., too strong inhibitory signals). b) Cancer immunotherapy is based around adjusting this balance to induce and sustain anti-tumor immune responses. Virtually all steps in immunological cascades have stimulatory and inhibitory signals acting on them, and drug delivery to specific immune cells and tissues to help control this balance pose opportunities for nanomaterials.

Despite these advances, the eradication of well-established tumors through the induction of immune responses remains difficult. A main reason for this is the complex and robust network of immunosuppressive pathways present in established tumors. The most promising results when treating complicated and advanced tumors have been achieved through the use of combination therapies that engage both innate and adaptive immune responses, ${ }^{292}$ locally and systemically. ${ }^{293}$ It is in this broader biological context that we believe cancer nanomedicine can have the greatest impact. 


\section{Outlook}

The field of nanomedicine is currently undergoing substantial changes, reinventing itself as old ideas become obsolete and are replaced by new directions and emerging concepts. ${ }^{294,295}$ At such a stage in the evolution of a field, it may be informative to look at neighboring fields for inspiration. A related area that has been part of cancer research for a longer time, so much so that it is today considered an integral part, is molecular biology. In a recent essay, ${ }^{296}$ Weinberg (one of the authors of the highly influential "Hallmarks of Cancer" paper ${ }^{34}$ ) outlines lessons from more than half-a-century of molecular biology in relation to cancer, and the wild fluctuations (both up and down) in confidence and enthusiasm that the field has experienced as it has matured. Some of these descriptions are similar to the experience and ongoing debate within cancer nanomedicine. Weinberg describes the early excitement among molecular biologists entering into cancer research as an atmosphere of feeling like "knights on white horses" about to "save the day" for the oncologists and clinicians who had toiled for so many years with only limited success. Armed with the new tools and the emerging power of molecular biology, the complexity of cancer could (the idea was) be reduced to easy, universally applicable rules that could then lead to cures. But despite many years of explosive growth in molecular biology, this did not happen. Since the initial enthusiasm and flurry of activity decades ago, Weinberg argues that molecular biology has gone (and is still going) through cycles of viewing cancer from perspectives ranging from simplistic reductionism to intractable complexity, as the field has matured to the point where it is today, where it is contributing both impactful scientific and clinical advances.

As the field of cancer nanomedicine is maturing, it is important to keep these lessons in mind: while it is not helpful to consider cancer a problem of intractable complexity, it is also not helpful to go too far down the path of reductionism, to reduce the complexity of the broad collection of diseases collectively known as cancer (and the associated human biology and disease pathology), to a set of "barriers" to be "overcome". Thinking of nanomedicine as a set of tools for "conquering biology" is engaging in a battle 
there is little chance of winning. Instead, we should consider the inherent properties of nanomedicine systems and work towards leveraging these. For example, if the vast majority of one type of intravenously injected nanoparticle gets sequestered in large, highly vascularized organs such as the liver and the lungs, can we use that to help arrest and sequester circulating (blood-borne) tumor cells or to prevent the formation of liver and lung metastasis, either directly or by inducing local mechanisms? And if another type of nanomaterial is instead subcutaneously injected and transported to lymph nodes where it strongly interacts with immune cells, can this be used for inducing anti-tumor immune responses? The key questions are: what are cancer nanomedicine systems good at, and how do we exploit these properties? How can we work with biology, and not against it?

Nanomaterials are having a growing impact on the on-going development of next generation therapeutics, and are indeed helping to redefine what we consider a medicine for cancer. By combining the concepts described herein with emerging broader themes such as the pursuit towards increasing robustness and convergence in science, ${ }^{13,297}$ along with the many innovative approaches being explored in oncology, nanomedicine has the potential to be transformative for the treatment of cancer.

\section{ASSOCIATED CONTENT}

The authors declare no competing financial interest.

\section{AUTHOR INFORMATION}

\section{Corresponding authors}

*E-mail: mattias.bjoernmalm@gmail.com

*E-mail: fcaruso@unimelb.edu.au

\section{Present Address}

M.B.: Department of Materials, Department of Bioengineering, and the Institute of Biomedical Engineering, Imperial College London, London SW7 2AZ, UK. 


\section{VOCABULARY}

Nanomedicine, leveraging the strengths of nanoscience and nanotechnology to achieve improved patient outcomes; Comparative oncology, the study of cancers that occurs naturally in animals (e.g., companion animals such as pet dogs); Syngeneic mouse tumor models, using immunocompetent mice-bearing tumors derived from the same mouse strain; Orthotopic mouse tumor models, tumors established by implanting cancer cells into the organ of origin (e.g., colon cancer cells implanted into the colon of mice instead of subcutaneously); Patient-derived tumor xenograft (PDX) mouse models, using cancerous tissue from patients (e.g., instead of cell lines) to establish tumors in mice; Transgenic tumor mouse models, mice genetically engineered with cancer-causing "oncogenes" that develop cancers spontaneously.

\section{ACKNOWLEDGEMENTS}

This research was supported by the Australian Research Council (ARC) under the Australian Laureate Fellowship scheme (FL120100030), and the ARC Centre of Excellence in Convergent Bio-Nano Science and Technology (Project No. CE140100036); the National Health and Medical Research Council (NHMRC) under the NHMRC Senior Practitioner Fellowship scheme (No. 1084178); and by the Victorian Government through an Infrastructure support program. We thank Alison E. Burke and Cassio Lynm for assistance with preparing Figure 1, and Matthew Faria, Paul Van de Ven, and Martin Björnmalm for critical reading of the manuscript and valuable discussions.

\section{References}

(1) Cui, J.; Richardson, J. J.; Björnmalm, M.; Faria, M.; Caruso, F. Nanoengineered Templated Polymer Particles: Navigating the Biological Realm. Acc. Chem. Res. 2016, 49, 1139-1148.

(2) Pelaz, B.; Alexiou, C.; Alvarez-Puebla, R. A.; Alves, F.; Andrews, A. M.; Ashraf, S.; Balogh, L. P.; Ballerini, L.; Bestetti, A.; Brendel, C.; Bosi, S.; Carril, M.; Chan, W. C. W.; Chen, C.; Chen, X.; Chen, X.; Cheng, Z.; Cui, D.; Du, J.; Dullin, C.; et al. Diverse Applications of Nanomedicine. ACS Nano 2017, 11, 2313-2381.

(3) Yang, X.; Yang, M.; Pang, B.; Vara, M.; Xia, Y. Gold Nanomaterials at Work in Biomedicine. Chem. Rev. 2015, 115, 10410-10488.

(4) Hühn, J.; Carrillo-Carrion, C.; Soliman, M. G.; Pfeiffer, C.; Valdeperez, D.; Masood, A.; 
Chakraborty, I.; Zhu, L.; Gallego, M.; Yue, Z.; Carril, M.; Feliu, N.; Escudero, A.; Alkilany, A. M.; Pelaz, B.; del Pino, P.; Parak, W. J. Selected Standard Protocols for the Synthesis, Phase Transfer, and Characterization of Inorganic Colloidal Nanoparticles. Chem. Mater. 2017, 29, 399461.

(5) Croissant, J. G.; Fatieiev, Y.; Khashab, N. M. Degradability and Clearance of Silicon, Organosilica, Silsesquioxane, Silica Mixed Oxide, and Mesoporous Silica Nanoparticles. Adv. Mater. 2017, 29, 1604634.

(6) Grimaldi, N.; Andrade, F.; Segovia, N.; Ferrer-Tasies, L.; Sala, S.; Veciana, J.; Ventosa, N. LipidBased Nanovesicles for Nanomedicine. Chem. Soc. Rev. 2016, 45, 6520-6545.

(7) Björnmalm, M.; Cui, J.; Bertleff-Zieschang, N.; Song, D.; Faria, M.; Rahim, M. A.; Caruso, F. Nanoengineering Particles through Template Assembly. Chem. Mater. 2017, 29, 289-306.

(8) Fang, R. H.; Jiang, Y.; Fang, J. C.; Zhang, L. Cell Membrane-Derived Nanomaterials for Biomedical Applications. Biomaterials 2017, 128, 69-83.

(9) Richardson, J. J.; Björnmalm, M.; Caruso, F. Technology-Driven Layer-by-Layer Assembly of Nanofilms. Science 2015, 348, aaa2491.

(10) Richardson, J. J.; Cui, J.; Björnmalm, M.; Braunger, J. A.; Ejima, H.; Caruso, F. Innovation in Layer-by-Layer Assembly. Chem. Rev. 2016, 116, 14828-14867.

(11) Kim, B. Y. S.; Rutka, J. T.; Chan, W. C. W. Nanomedicine. N. Engl. J. Med. 2010, 363, 24342443.

(12) Langer, R.; Weissleder, R. Nanotechnology. JAMA 2015, 313, 135-136.

(13) Björnmalm, M.; Faria, M.; Caruso, F. Increasing the Impact of Materials in and beyond Bio-Nano Science. J. Am. Chem. Soc. 2016, 138, 13449-13456.

(14) Shi, J.; Kantoff, P. W.; Wooster, R.; Farokhzad, O. C. Cancer Nanomedicine: Progress, Challenges and Opportunities. Nat. Rev. Cancer 2016, 17, 20-37.

(15) von Roemeling, C.; Jiang, W.; Chan, C. K.; Weissman, I. L.; Kim, B. Y. S. Breaking Down the Barriers to Precision Cancer Nanomedicine. Trends Biotechnol. 2017, 35, 159-171.

(16) Tong, R.; Kohane, D. S. New Strategies in Cancer Nanomedicine. Annu. Rev. Pharmacol. Toxicol. 2016, 56, 41-57.

(17) Balasubramanian, V.; Liu, Z.; Hirvonen, J.; Santos, H. A. Bridging the Knowledge of Different Worlds to Understand the Big Picture of Cancer Nanomedicines. Adv. Healthcare Mater. 2017, in press. DOI: 10.1002/adhm.201700432.

(18) van der Meel, R.; Lammers, T.; Hennink, W. E. Cancer Nanomedicines: Oversold or Underappreciated? Expert Opin. Drug Deliv. 2017, 14, 1-5.

(19) Cancer Targeted Drug Delivery: An Elusive Dream; Bae, Y. H., Mrsny, R. J., Park, K., Eds.; Springer-Verlag: New York, NY, USA, ISBN: 9781461478751, 2013.

(20) Moghimi, S. M.; Farhangrazi, Z. S. Just so Stories: The Random Acts of Anti-Cancer Nanomedicine Performance. Nanomed. Nanotechnol. Biol. Med. 2014, 10, 1661-1666.

(21) Treatment of Cancer, 6th ed.; Price, P., Sikora, K., Eds.; CRC Press: Boca Raton, Florida, USA, ISBN: $9781482214949,2014$. 
(22) Disease Control Priorities: Cancer, 3rd ed.; Gelband, H., Jha, P., Sankaranarayanan, R., Horton, S., Eds.; The World Bank: Washington, DC, USA, ISBN: 9781464803499, 2015.

(23) Chabner, B. A.; Roberts, T. G. Chemotherapy and the War on Cancer. Nat. Rev. Cancer 2005, 5, $65-72$.

(24) DeVita, V. T.; Chu, E. A History of Cancer Chemotherapy. Cancer Res. 2008, 68, 8643-8653.

(25) Massagué, J.; Obenauf, A. C. Metastatic Colonization by Circulating Tumour Cells. Nature 2016, 529, 298-306.

(26) Schroeder, A.; Heller, D. A.; Winslow, M. M.; Dahlman, J. E.; Pratt, G. W.; Langer, R.; Jacks, T.; Anderson, D. G. Treating Metastatic Cancer with Nanotechnology. Nat. Rev. Cancer 2011, 12, $39-50$.

(27) Petersen, G. H.; Alzghari, S. K.; Chee, W.; Sankari, S. S.; La-Beck, N. M. Meta-Analysis of Clinical and Preclinical Studies Comparing the Anticancer Efficacy of Liposomal versus Conventional Non-Liposomal Doxorubicin. J. Controlled Release 2016, 232, 255-264.

(28) Stylianopoulos, T.; Jain, R. K. Design Considerations for Nanotherapeutics in Oncology. Nanomed. Nanotechnol. Biol. Med. 2015, 11, 1893-1907.

(29) Meacham, C. E.; Morrison, S. J. Tumour Heterogeneity and Cancer Cell Plasticity. Nature 2013, $501,328-337$.

(30) Bedard, P. L.; Hansen, A. R.; Ratain, M. J.; Siu, L. L. Tumour Heterogeneity in the Clinic. Nature 2013, 501, 355-364.

(31) Vogelstein, B.; Papadopoulos, N.; Velculescu, V. E.; Zhou, S.; Diaz, L. A.; Kinzler, K. W. Cancer Genome Landscapes. Science 2013, 339, 1546-1558.

(32) Alizadeh, A. A.; Aranda, V.; Bardelli, A.; Blanpain, C.; Bock, C.; Borowski, C.; Caldas, C.; Califano, A.; Doherty, M.; Elsner, M.; Esteller, M.; Fitzgerald, R.; Korbel, J. O.; Lichter, P.; Mason, C. E.; Navin, N.; Pe'er, D.; Polyak, K.; Roberts, C. W. M.; Siu, L.; et al. Toward Understanding and Exploiting Tumor Heterogeneity. Nat. Med. 2015, 21, 846-853.

(33) Junttila, M. R.; de Sauvage, F. J. Influence of Tumour Micro-Environment Heterogeneity on Therapeutic Response. Nature 2013, 501, 346-354.

(34) Hanahan, D.; Weinberg, R. A. Hallmarks of Cancer: The Next Generation. Cell 2011, 144, 646674.

(35) Flavahan, W. A.; Gaskell, E.; Bernstein, B. E. Epigenetic Plasticity and the Hallmarks of Cancer. Science 2017, 357, eaal2380.

(36) Jain, R. K. Vascular and Interstitial Barriers to Delivery of Therapeutic Agents in Tumors. Cancer Metastasis Rev. 1990, 9, 253-266.

(37) Minchinton, A. I.; Tannock, I. F. Drug Penetration in Solid Tumours. Nat. Rev. Cancer 2006, 6, $583-592$.

(38) Thurber, G. M.; Schmidt, M. M.; Wittrup, K. D. Antibody Tumor Penetration: Transport Opposed by Systemic and Antigen-Mediated Clearance. Adv. Drug Deliv. Rev. 2008, 60, 1421-1434.

(39) Ekdawi, S. N.; Jaffray, D. A.; Allen, C. Nanomedicine and Tumor Heterogeneity: Concept and Complex Reality. Nano Today 2016, 11, 402-414. 
(40) Goldacre, R. J.; Sylven, B. A Rapid Method for Studying Tumour Blood Supply Using Systemic Dyes. Nature 1959, 184, 63-64.

(41) Owen, L. N. A Rapid Method for Studying Tumour Blood Supply Using Lissamine Green. Nature 1960, 187, 795-796.

(42) Goldacre, R. J.; Sylven, B. On the Access of Blood-Borne Dyes to Various Tumour Regions. Br. J. Cancer 1962, 16, 306-322.

(43) Gerlowski, L. E.; Jain, R. K. Microvascular Permeability of Normal and Neoplastic Tissues. Microvasc. Res. 1986, 31, 288-305.

(44) Matsumura, Y.; Maeda, H. A New Concept for Macromolecular Therapeutics in Cancer Chemotherapy: Mechanism of Tumoritropic Accumulation of Proteins and the Antitumor Agent Smancs. Cancer Res. 1986, 46, 6387-6392.

(45) Nichols, J. W.; Bae, Y. H. EPR: Evidence and Fallacy. J. Controlled Release 2014, 190, 451-464.

(46) Nakamura, H.; Jun, F.; Maeda, H. Development of next-Generation Macromolecular Drugs Based on the EPR Effect: Challenges and Pitfalls. Expert Opin. Drug Deliv. 2015, 12, 53-64.

(47) Prabhakar, U.; Maeda, H.; Jain, R. K.; Sevick-Muraca, E. M.; Zamboni, W.; Farokhzad, O. C.; Barry, S. T.; Gabizon, A.; Grodzinski, P.; Blakey, D. C. Challenges and Key Considerations of the Enhanced Permeability and Retention Effect for Nanomedicine Drug Delivery in Oncology. Cancer Res. 2013, 73, 2412-2417.

(48) Huynh, E.; Zheng, G. Cancer Nanomedicine: Addressing the Dark Side of the Enhanced Permeability and Retention Effect. Nanomedicine 2015, 10, 1993-1995.

(49) Nakamura, Y.; Mochida, A.; Choyke, P. L.; Kobayashi, H. Nanodrug Delivery: Is the Enhanced Permeability and Retention Effect Sufficient for Curing Cancer? Bioconjugate Chem. 2016, 27, $2225-2238$.

(50) Danhier, F. To Exploit the Tumor Microenvironment: Since the EPR Effect Fails in the Clinic, What Is the Future of Nanomedicine? J. Controlled Release 2016, 244, 108-121.

(51) Anchordoquy, T. J.; Barenholz, Y.; Boraschi, D.; Chorny, M.; Decuzzi, P.; Dobrovolskaia, M. A.; Farhangrazi, Z. S.; Farrell, D.; Gabizon, A.; Ghandehari, H.; Godin, B.; La-Beck, N. M.; Ljubimova, J.; Moghimi, S. M.; Pagliaro, L.; Park, J.-H.; Peer, D.; Ruoslahti, E.; Serkova, N. J.; Simberg, D. Mechanisms and Barriers in Cancer Nanomedicine: Addressing Challenges, Looking for Solutions. ACS Nano 2017, 11, 12-18.

(52) Harrington, K. J.; Mohammadtaghi, S.; Uster, P. S.; Glass, D.; Peters, A. M.; Vile, R. G.; Stewart, J. S. Effective Targeting of Solid Tumors in Patients with Locally Advanced Cancers by Radiolabeled Pegylated Liposomes. Clin. Cancer Res. 2001, 7, 243-254.

(53) Presant, C. A.; Blayney, D.; Proffitt, R. T.; Turner, A. F.; Williams, L. E.; Nadel, H. I.; Kennedy, P.; Wiseman, C.; Gala, K.; Crossley, R. J. Preliminary Report: Imaging of Kaposi Sarcoma and Lymphoma in AIDS with Indium-111-Labelled Liposomes. Lancet 1990, 335, 1307-1309.

(54) Briele, B.; Hotze, A.; Oehr, P.; Biersack, H. J.; Rosanowski, F.; Gorgulla, W.; Herberhold, C.; Hartlapp, J. P. Tumour Imaging with Labelled Liposomes. Lancet 1990, 336, 875-876.

(55) Khalifa, A.; Dodds, D.; Rampling, R.; Paterson, J.; Murray, T. Liposomal Distribution in Malignant Glioma: Possibilities for Therapy. Nucl. Med. Commun. 1997, 18, 17-23.

(56) Presant, C. A.; Proffitt, R. T.; Turner, A. F.; Williams, L. E.; Winsor, D.; Werner, J. L.; Kennedy, 
P.; Wiseman, C.; Gala, K.; McKenna, R. J.; Smith, J. D.; Bouzaglou, S. A.; Callahan, R. A.; Baldeschwieler, J.; Crossley, R. J. Successful Imaging of Human Cancer with Indium-111Labeled Phospholipid Vesicles. Cancer 1988, 62, 905-911.

(57) Clark, A. J.; Wiley, D. T.; Zuckerman, J. E.; Webster, P.; Chao, J.; Lin, J.; Yen, Y.; Davis, M. E. CRLX101 Nanoparticles Localize in Human Tumors and Not in Adjacent, Nonneoplastic Tissue after Intravenous Dosing. Proc. Natl. Acad. Sci. U. S. A. 2016, 113, 3850-3854.

(58) Barenholz, Y. Doxil - The First FDA-Approved Nano-Drug: Lessons Learned. J. Controlled Release 2012, 160, 117-134.

(59) Northfelt, D. W.; Dezube, B. J.; Thommes, J. A.; Miller, B. J.; Fischl, M. A.; Friedman-Kien, A.; Kaplan, L. D.; Du Mond, C.; Mamelok, R. D.; Henry, D. H. Pegylated-Liposomal Doxorubicin versus Doxorubicin, Bleomycin, and Vincristine in the Treatment of AIDS-Related Kaposi's Sarcoma: Results of a Randomized Phase III Clinical Trial. J. Clin. Oncol. 1998, 16, 2445-2451.

(60) O’Brien, M. E. R.; Wigler, N.; Inbar, M.; Rosso, R.; Grischke, E.; Santoro, A.; Catane, R.; Kieback, D. G.; Tomczak, P.; Ackland, S. P.; Orlandi, F.; Mellars, L.; Alland, L.; Tendler, C.; CAELYX Breast Cancer Study Group. Reduced Cardiotoxicity and Comparable Efficacy in a Phase III Trial of Pegylated Liposomal Doxorubicin HCl (CAELYX/Doxil) versus Conventional Doxorubicin for First-Line Treatment of Metastatic Breast Cancer. Ann. Oncol. 2004, 15, 440 449.

(61) Hansen, A. E.; Petersen, A. L.; Henriksen, J. R.; Boerresen, B.; Rasmussen, P.; Elema, D. R.; Rosenschöld, P. M. af; Kristensen, A. T.; Kjær, A.; Andresen, T. L. Positron Emission Tomography Based Elucidation of the Enhanced Permeability and Retention Effect in Dogs with Cancer Using Copper-64 Liposomes. ACS Nano 2015, 9, 6985-6995.

(62) LeBlanc, A. K.; Breen, M.; Choyke, P.; Dewhirst, M.; Fan, T. M.; Gustafson, D. L.; Helman, L. J.; Kastan, M. B.; Knapp, D. W.; Levin, W. J.; London, C.; Mason, N.; Mazcko, C.; Olson, P. N.; Page, R.; Teicher, B. A.; Thamm, D. H.; Trent, J. M.; Vail, D. M.; Khanna, C. Perspectives from Mans Best Friend: National Academy of Medicines Workshop on Comparative Oncology. Sci. Transl. Med. 2016, 8, 324ps5.

(63) LeBlanc, A. K.; Mazcko, C. N.; Khanna, C. Defining the Value of a Comparative Approach to Cancer Drug Development. Clin. Cancer Res. 2016, 22, 2133-2138.

(64) Natfji, A. A.; Ravishankar, D.; Osborn, H. M. I.; Greco, F. Parameters Affecting the Enhanced Permeability and Retention Effect: The Need for Patient Selection. J. Pharm. Sci. 2017, in press. DOI: $10.1016 /$ j.xphs.2017.06.019.

(65) Judenhofer, M. S.; Wehrl, H. F.; Newport, D. F.; Catana, C.; Siegel, S. B.; Becker, M.; Thielscher, A.; Kneilling, M.; Lichy, M. P.; Eichner, M.; Klingel, K.; Reischl, G.; Widmaier, S.; Röcken, M.; Nutt, R. E.; Machulla, H.-J.; Uludag, K.; Cherry, S. R.; Claussen, C. D.; Pichler, B. J.

Simultaneous PET-MRI: A New Approach for Functional and Morphological Imaging. Nat. Med. 2008, 14, 459-465.

(66) Thorek, D. L. J.; Ulmert, D.; Diop, N.-F. M.; Lupu, M. E.; Doran, M. G.; Huang, R.; Abou, D. S.; Larson, S. M.; Grimm, J. Non-Invasive Mapping of Deep-Tissue Lymph Nodes in Live Animals Using a Multimodal PET/MRI Nanoparticle. Nat. Commun. 2014, 5, 3097.

(67) Cheon, J.; Lee, J.-H. Synergistically Integrated Nanoparticles as Multimodal Probes for Nanobiotechnology. Acc. Chem. Res. 2008, 41, 1630-1640.

(68) Puttick, S.; Boase, N. R. B.; Blakey, I.; Thurecht, K. J. Imaging Tumour Distribution of a 
Polymeric Drug Delivery Platform In Vivo by PET-MRI. J. Chem. Technol. Biotechnol. 2015, 90, $1237-1244$.

(69) Fuchs, A. V.; Tse, B. W. C.; Pearce, A. K.; Yeh, M.-C.; Fletcher, N. L.; Huang, S. S.; Heston, W. D.; Whittaker, A. K.; Russell, P. J.; Thurecht, K. J. Evaluation of Polymeric Nanomedicines Targeted to PSMA: Effect of Ligand on Targeting Efficiency. Biomacromolecules 2015, 16, $3235-3247$.

(70) Bae, Y. H.; Park, K. Targeted Drug Delivery to Tumors: Myths, Reality and Possibility. J. Controlled Release 2011, 153, 198-205.

(71) Florence, A. T. "Targeting” Nanoparticles: The Constraints of Physical Laws and Physical Barriers. J. Controlled Release 2012, 164, 115-124.

(72) Kwon, I. K.; Lee, S. C.; Han, B.; Park, K. Analysis on the Current Status of Targeted Drug Delivery to Tumors. J. Controlled Release 2012, 164, 108-114.

(73) Park, K. Facing the Truth about Nanotechnology in Drug Delivery. ACS Nano 2013, 7, 74427447.

(74) Lammers, T.; Kiessling, F.; Hennink, W. E.; Storm, G. Drug Targeting to Tumors: Principles, Pitfalls and (Pre-) Clinical Progress. J. Controlled Release 2012, 161, 175-187.

(75) Park, K. Drug Delivery of the Future: Chasing the Invisible Gorilla. J. Controlled Release 2016, 240, 2-8.

(76) Wilhelm, S.; Tavares, A. J.; Dai, Q.; Ohta, S.; Audet, J.; Dvorak, H. F.; Chan, W. C. W. Analysis of Nanoparticle Delivery to Tumours. Nat. Rev. Mater. 2016, 1, 16014.

(77) McNeil, S. E. Evaluation of Nanomedicines: Stick to the Basics. Nat. Rev. Mater. 2016, 1, 16073.

(78) Wilhelm, S.; Tavares, A. J.; Chan, W. C. W. Reply to "Evaluation of Nanomedicines: Stick to the Basics." Nat. Rev. Mater. 2016, 1, 16074.

(79) Torrice, M. Does Nanomedicine Have a Delivery Problem? ACS Cent. Sci. 2016, 2, 434-437.

(80) Lammers, T.; Kiessling, F.; Ashford, M.; Hennink, W.; Crommelin, D.; Strom, G. Cancer Nanomedicine: Is Targeting Our Target? Nat. Rev. Mater. 2016, 1, 16069.

(81) Scott, A. M.; Wolchok, J. D.; Old, L. J. Antibody Therapy of Cancer. Nat. Rev. Cancer 2012, 12, $278-287$.

(82) Sliwkowski, M. X.; Mellman, I. Antibody Therapeutics in Cancer. Science 2013, 341, 1192-1198.

(83) Weiner, G. J. Building Better Monoclonal Antibody-Based Therapeutics. Nat. Rev. Cancer 2015, $15,361-370$.

(84) Contributions to Oncology: Monoclonal Antibodies in Tumor Therapy; Sedlacek, H. H., Schulz, G., Steinstraesser, A., Kuhlman, L., Schwarz, A., Seidel, L., Seemann, G., Kraemer, H. P., Bosslet, K., Eds.; Karger: Basel, Switzerland, ISBN: 9783805547635, 1988.

(85) Press, O. W.; Eary, J. F.; Badger, C. C.; Martin, P. J.; Appelbaum, F. R.; Levy, R.; Miller, R.; Brown, S.; Nelp, W. B.; Krohn, K. A. Treatment of Refractory Non-Hodgkin's Lymphoma with Radiolabeled MB-1 (Anti-CD37) Antibody. J. Clin. Oncol. 1989, 7, 1027-1038.

(86) DeNardo, S. J.; O’Grady, L. F.; Anderson, L. E.; Macey, D. J. Successful Serial Radioimmunotherapy in Spite of HAMA Response. In Proceedings of the 36th Annual Meeting of 
The Society of Nuclear Medicine; 1989; p 827.

(87) Scheinberg, D. A.; Lovett, D.; Divgi, C. R.; Graham, M. C.; Berman, E.; Pentlow, K.; Feirt, N.; Finn, R. D.; Clarkson, B. D.; Gee, T. S. A Phase I Trial of Monoclonal Antibody M195 in Acute Myelogenous Leukemia: Specific Bone Marrow Targeting and Internalization of Radionuclide. $J$. Clin. Oncol. 1991, 9, 478-490.

(88) Miraldi, F. D.; Nelson, A. D.; Kraly, C.; Ellery, S.; Landmeier, B.; Coccia, P. F.; Strandjord, S. E.; Cheung, N. K. Diagnostic Imaging of Human Neuroblastoma with Radiolabeled Antibody. Radiology 1986, 161, 413-418.

(89) Colcher, D.; Esteban, J. M.; Carrasquillo, J. A.; Sugarbaker, P.; Reynolds, J. C.; Bryant, G.; Larson, S. M.; Schlom, J. Quantitative Analyses of Selective Radiolabeled Monoclonal Antibody Localization in Metastatic Lesions of Colorectal Cancer Patients. Cancer Res. 1987, 47, 1185 1189 .

(90) Scott, A. M.; Lee, F.-T.; Jones, R.; Hopkins, W.; MacGregor, D.; Cebon, J. S.; Hannah, A.; Chong, G.; U, P.; Papenfuss, A.; Rigopoulos, A.; Sturrock, S.; Murphy, R.; Wirth, V.; Murone, C.; Smyth, F. E.; Knight, S.; Welt, S.; Ritter, G.; Richards, E.; et al. A Phase I Trial of Humanized Monoclonal Antibody A33 in Patients with Colorectal Carcinoma: Biodistribution, Pharmacokinetics, and Quantitative Tumor Uptake. Clin. Cancer Res. 2005, 11, 4810-4817.

(91) Beatty, J. D.; Duda, R. B.; Williams, L. E.; Sheibani, K.; Paxton, R. J.; Beatty, B. G.; Philben, V. J.; Werner, J. L.; Shively, J. E.; Vlahos, W. G. Preoperative Imaging of Colorectal Carcinoma with 111 In-Labeled Anticarcinoembryonic Antigen Monoclonal Antibody. Cancer Res. 1986, 46, 6494-6502.

(92) Armitage, N. C.; Perkins, A. C.; Pimm, M. V; Wastie, M. L.; Baldwin, R. W.; Hardcastle, J. D. Imaging of Primary and Metastatic Colorectal Cancer Using an 111In-Labelled Antitumour Monoclonal Antibody (791T/36). Nucl. Med. Commun. 1985, 6, 623-631.

(93) Epenetos, A. A.; Carr, D.; Johnson, P. M.; Bodmer, W. F.; Lavender, J. P. Antibody-Guided Radiolocalisation of Tumours in Patients with Testicular or Ovarian Cancer Using Two Radioiodinated Monoclonal Antibodies to Placental Alkaline Phosphatase. Br. J. Radiol. 1986, 59, $117-125$.

(94) Powell, M. C.; Perkins, A. C.; Pimm, M. V; Jetaily, M. A.; Wastie, M. L.; Durrant, L.; Baldwin, R. W.; Symonds, E. M. Diagnostic Imaging of Gynecologic Tumors with the Monoclonal Antibody 791T/36. Am. J. Obstet. Gynecol. 1987, 157, 28-34.

(95) Scott, A. M.; Lee, F.-T.; Tebbutt, N.; Herbertson, R.; Gill, S. S.; Liu, Z.; Skrinos, E.; Murone, C.; Saunder, T. H.; Chappell, B.; Papenfuss, A. T.; Poon, A. M. T.; Hopkins, W.; Smyth, F. E.; MacGregor, D.; Cher, L. M.; Jungbluth, A. A.; Ritter, G.; Brechbiel, M. W.; Murphy, R.; et al. A Phase I Clinical Trial with Monoclonal Antibody ch806 Targeting Transitional State and Mutant Epidermal Growth Factor Receptors. Proc. Natl. Acad. Sci. U. S. A. 2007, 104, 4071-4076.

(96) Scott, A. M.; Lee, F.-T.; Hopkins, W.; Cebon, J. S.; Wheatley, J. M.; Liu, Z.; Smyth, F. E.; Murone, C.; Sturrock, S.; MacGregor, D.; Hanai, N.; Inoue, K.; Yamasaki, M.; Brechbiel, M. W.; Davis, I. D.; Murphy, R.; Hannah, A.; Lim-Joon, M.; Chan, T.; Chong, G.; et al. Specific Targeting, Biodistribution, and Lack of Immunogenicity of Chimeric Anti-GD3 Monoclonal Antibody KM871 in Patients With Metastatic Melanoma: Results of a Phase I Trial. J. Clin. Oncol. 2001, 19, 3976-3987.

(97) Buraggi, G. L.; Callegaro, L.; Mariani, G.; Turrin, A.; Cascinelli, N.; Attili, A.; Bombardieri, E.; Terno, G.; Plassio, G.; Dovis, M. Imaging with 131I-Labeled Monoclonal Antibodies to a High- 
Molecular-Weight Melanoma-Associated Antigen in Patients with Melanoma: Efficacy of Whole Immunoglobulin and Its F(ab')2 Fragments. Cancer Res. 1985, 45, 3378-3387.

(98) Greager, J. A.; Brown, J. M.; Pavel, D. G.; Garcia, J. L.; Blend, M.; Das Gupta, T. K. Localization of Human Sarcoma with Radiolabeled Monoclonal Antibody. Cancer Immunol. Immunother. 1986, 23, 148-154.

(99) Chari, R. V. J. Targeted Cancer Therapy: Conferring Specificity to Cytotoxic Drugs. Acc. Chem. Res. 2008, 41, 98-107.

(100) Contributions to Oncology: Antibodies as Carriers of Cytotoxicity; Sedlacek, H. H., Seemann, G., Hoffmann, D., Czech, J., Lorenz, P., Kolar, C., Bosslet, K., Eds.; Karger: Basel, Switzerland, ISBN: $9783805555999,1992$.

(101) Weinstein, J. N.; Eger, R. R.; Covell, D. G.; Black, C. D. V.; Mulshine, J.; Carrasquillo, J. A.; Larson, S. M.; Keenan, A. M. The Pharmacology of Monoclonal Antibodies. Ann. N. Y. Acad. Sci. 1987, 507, 199-210.

(102) Vaneycken, I.; D’huyvetter, M.; Hernot, S.; De Vos, J.; Xavier, C.; Devoogdt, N.; Caveliers, V.; Lahoutte, T. Immuno-Imaging Using Nanobodies. Curr. Opin. Biotechnol. 2011, 22, 877-881.

(103) Nilvebrant, J.; Tessier, P.; Sidhu, S. Engineered Autonomous Human Variable Domains. Curr. Pharm. Des. 2016, 22, 6527-6537.

(104) Boersma, Y. L.; Plückthun, A. DARPins and Other Repeat Protein Scaffolds: Advances in Engineering and Applications. Curr. Opin. Biotechnol. 2011, 22, 849-857.

(105) Nilvebrant, J.; Åstrand, M.; Georgieva-Kotseva, M.; Björnmalm, M.; Löfblom, J.; Hober, S. Engineering of Bispecific Affinity Proteins with High Affinity for ERBB2 and Adaptable Binding to Albumin. PLoS One 2014, 9, e103094.

(106) Åstrand, M.; Nilvebrant, J.; Björnmalm, M.; Lindbo, S.; Hober, S.; Löfblom, J. Investigating Affinity-Maturation Strategies and Reproducibility of Fluorescence-Activated Cell Sorting Using a Recombinant ADAPT Library Displayed on Staphylococci. Protein Eng. Des. Sel. 2016, 29, $187-195$.

(107) Löfblom, J.; Frejd, F. Y.; Ståhl, S. Non-Immunoglobulin Based Protein Scaffolds. Curr. Opin. Biotechnol. 2011, 22, 843-848.

(108) Sandstrom, M.; Lindskog, K.; Velikyan, I.; Wennborg, A.; Feldwisch, J.; Sandberg, D.; Tolmachev, V.; Orlova, A.; Sorensen, J.; Carlsson, J.; Lindman, H.; Lubberink, M. Biodistribution and Radiation Dosimetry of the Anti-HER2 Affibody Molecule 68Ga-ABY-025 in Breast Cancer Patients. J. Nucl. Med. 2016, 57, 867-871.

(109) Keyaerts, M.; Xavier, C.; Heemskerk, J.; Devoogdt, N.; Everaert, H.; Ackaert, C.; Vanhoeij, M.; Duhoux, F. P.; Gevaert, T.; Simon, P.; Schallier, D.; Fontaine, C.; Vaneycken, I.; Vanhove, C.; De Greve, J.; Lamote, J.; Caveliers, V.; Lahoutte, T. Phase I Study of 68Ga-HER2-Nanobody for PET/CT Assessment of HER2 Expression in Breast Carcinoma. J. Nucl. Med. 2016, 57, 27-33.

(110) Sorensen, J.; Sandberg, D.; Sandstrom, M.; Wennborg, A.; Feldwisch, J.; Tolmachev, V.; Astrom, G.; Lubberink, M.; Garske-Roman, U.; Carlsson, J.; Lindman, H. First-in-Human Molecular Imaging of HER2 Expression in Breast Cancer Metastases Using the 111In-ABY-025 Affibody Molecule. J. Nucl. Med. 2014, 55, 730-735.

(111) Thomas, A.; Teicher, B. A.; Hassan, R. Antibody-drug Conjugates for Cancer Therapy. Lancet Oncol. 2016, 17, e254-e262. 
(112) Chudasama, V.; Maruani, A.; Caddick, S. Recent Advances in the Construction of Antibody-drug Conjugates. Nat. Chem. 2016, 8, 114-119.

(113) Shargh, V. H.; Hondermarck, H.; Liang, M. Antibody-Targeted Biodegradable Nanoparticles for Cancer Therapy. Nanomedicine 2016, 11, 63-79.

(114) Dai, Q.; Yan, Y.; Guo, J.; Björnmalm, M.; Cui, J.; Sun, H.; Caruso, F. Targeting Ability of Affibody-Functionalized Particles Is Enhanced by Albumin but Inhibited by Serum Coronas. ACS Macro Lett. 2015, 4, 1259-1263.

(115) Solomon, B. J.; Desai, J.; Rosenthal, M.; McArthur, G. A.; Pattison, S. T.; Pattison, S. L.; MacDiarmid, J.; Brahmbhatt, H.; Scott, A. M. A First-Time-In-Human Phase I Clinical Trial of Bispecific Antibody-Targeted, Paclitaxel-Packaged Bacterial Minicells. PLoS One 2015, 10, e0144559.

(116) Howard, C. B.; Fletcher, N.; Houston, Z. H.; Fuchs, A. V.; Boase, N. R. B.; Simpson, J. D.; Raftery, L. J.; Ruder, T.; Jones, M. L.; de Bakker, C. J.; Mahler, S. M.; Thurecht, K. J.

Overcoming Instability of Antibody-Nanomaterial Conjugates: Next Generation Targeted Nanomedicines Using Bispecific Antibodies. Adv. Healthcare Mater. 2016, 5, 2055-2068.

(117) Kirpotin, D. B.; Drummond, D. C.; Shao, Y.; Shalaby, M. R.; Hong, K.; Nielsen, U. B.; Marks, J. D.; Benz, C. C.; Park, J. W. Antibody Targeting of Long-Circulating Lipidic Nanoparticles Does Not Increase Tumor Localization but Does Increase Internalization in Animal Models. Cancer Res. 2006, 66, 6732-6740.

(118) Bartlett, D. W.; Su, H.; Hildebrandt, I. J.; Weber, W. A.; Davis, M. E. Impact of Tumor-Specific Targeting on the Biodistribution and Efficacy of siRNA Nanoparticles Measured by Multimodality In Vivo Imaging. Proc. Natl. Acad. Sci. U. S. A. 2007, 104, 15549-15554.

(119) Huang, X.; Peng, X.; Wang, Y.; Wang, Y.; Shin, D. M.; El-Sayed, M. A.; Nie, S. A Reexamination of Active and Passive Tumor Targeting by Using Rod-Shaped Gold Nanocrystals and Covalently Conjugated Peptide Ligands. ACS Nano 2010, 4, 5887-5896.

(120) Schleich, N.; Po, C.; Jacobs, D.; Ucakar, B.; Gallez, B.; Danhier, F.; Préat, V. Comparison of Active, Passive and Magnetic Targeting to Tumors of Multifunctional paclitaxel/SPIO-Loaded Nanoparticles for Tumor Imaging and Therapy. J. Controlled Release 2014, 194, 82-91.

(121) Pirollo, K. F.; Chang, E. H. Does a Targeting Ligand Influence Nanoparticle Tumor Localization or Uptake? Trends Biotechnol. 2008, 26, 552-558.

(122) Choi, C. H. J.; Alabi, C. A.; Webster, P.; Davis, M. E. Mechanism of Active Targeting in Solid Tumors with Transferrin-Containing Gold Nanoparticles. Proc. Natl. Acad. Sci. U. S. A. 2010, 107, 1235-1240.

(123) Johnston, A. P. R.; Kamphuis, M. M. J.; Such, G. K.; Scott, A. M.; Nice, E. C.; Heath, J. K.; Caruso, F. Targeting Cancer Cells: Controlling the Binding and Internalization of AntibodyFunctionalized Capsules. ACS Nano 2012, 6, 6667-6674.

(124) Mintern, J. D.; Percival, C.; Kamphuis, M. M. J.; Chin, W. J.; Caruso, F.; Johnston, A. P. R. Targeting Dendritic Cells: The Role of Specific Receptors in the Internalization of Polymer Capsules. Adv. Healthcare Mater. 2013, 2, 940-944.

(125) Wang, Y.; Huang, L. A Window onto siRNA Delivery. Nat. Biotechnol. 2013, 31, 611-612.

(126) Sahay, G.; Querbes, W.; Alabi, C.; Eltoukhy, A.; Sarkar, S.; Zurenko, C.; Karagiannis, E.; Love, K.; Chen, D.; Zoncu, R.; Buganim, Y.; Schroeder, A.; Langer, R.; Anderson, D. G. Efficiency of 
siRNA Delivery by Lipid Nanoparticles Is Limited by Endocytic Recycling. Nat. Biotechnol. 2013, 31, 653-658.

(127) Behzadi, S.; Serpooshan, V.; Tao, W.; Hamaly, M. A.; Alkawareek, M. Y.; Dreaden, E. C.; Brown, D.; Alkilany, A. M.; Farokhzad, O. C.; Mahmoudi, M. Cellular Uptake of Nanoparticles: Journey inside the Cell. Chem. Soc. Rev. 2017, 46, 4218-4244.

(128) Gilleron, J.; Querbes, W.; Zeigerer, A.; Borodovsky, A.; Marsico, G.; Schubert, U.; Manygoats, K.; Seifert, S.; Andree, C.; Stöter, M.; Epstein-Barash, H.; Zhang, L.; Koteliansky, V.; Fitzgerald, K.; Fava, E.; Bickle, M.; Kalaidzidis, Y.; Akinc, A.; Maier, M.; Zerial, M. Image-Based Analysis of Lipid Nanoparticle-mediated siRNA Delivery, Intracellular Trafficking and Endosomal Escape. Nat. Biotechnol. 2013, 31, 638-646.

(129) Hadjidemetriou, M.; Kostarelos, K. Nanomedicine: Evolution of the Nanoparticle Corona. Nat. Nanotechnol. 2017, 12, 288-290.

(130) Lara, S.; Alnasser, F.; Polo, E.; Garry, D.; Lo Giudice, M. C.; Hristov, D. R.; Rocks, L.; Salvati, A.; Yan, Y.; Dawson, K. A. Identification of Receptor Binding to the Biomolecular Corona of Nanoparticles. ACS Nano 2017, 11, 1884-1893.

(131) Smith, B. R.; Zavaleta, C.; Rosenberg, J.; Tong, R.; Ramunas, J.; Liu, Z.; Dai, H.; Gambhir, S. S. High-Resolution, Serial Intravital Microscopic Imaging of Nanoparticle Delivery and Targeting in a Small Animal Tumor Model. Nano Today 2013, 8, 126-137.

(132) Kunjachan, S.; Pola, R.; Gremse, F.; Theek, B.; Ehling, J.; Moeckel, D.; Hermanns-Sachweh, B.; Pechar, M.; Ulbrich, K.; Hennink, W. E.; Storm, G.; Lederle, W.; Kiessling, F.; Lammers, T. Passive versus Active Tumor Targeting Using RGD- and NGR-Modified Polymeric Nanomedicines. Nano Lett. 2014, 14, 972-981.

(133) Singh, R.; Norret, M.; House, M. J.; Galabura, Y.; Bradshaw, M.; Ho, D.; Woodward, R. C.; Pierre, T. G. St.; Luzinov, I.; Smith, N. M.; Lim, L. Y.; Iyer, K. S. Dose-Dependent Therapeutic Distinction between Active and Passive Targeting Revealed Using Transferrin-Coated PGMA Nanoparticles. Small 2016, 12, 351-359.

(134) Sykes, E. A.; Chen, J.; Zheng, G.; Chan, W. C. W. Investigating the Impact of Nanoparticle Size on Active and Passive Tumor Targeting Efficiency. ACS Nano 2014, 8, 5696-5706.

(135) Colombo, M.; Fiandra, L.; Alessio, G.; Mazzucchelli, S.; Nebuloni, M.; De Palma, C.; Kantner, K.; Pelaz, B.; Rotem, R.; Corsi, F.; Parak, W. J.; Prosperi, D. Tumour Homing and Therapeutic Effect of Colloidal Nanoparticles Depend on the Number of Attached Antibodies. Nat. Commun. 2016, 7, 13818.

(136) Reuter, K. G.; Perry, J. L.; Kim, D.; Luft, J. C.; Liu, R.; DeSimone, J. M. Targeted PRINT Hydrogels: The Role of Nanoparticle Size and Ligand Density on Cell Association, Biodistribution, and Tumor Accumulation. Nano Lett. 2015, 15, 6371-6378.

(137) Herda, L. M.; Hristov, D. R.; Lo Giudice, M. C.; Polo, E.; Dawson, K. A. Mapping of Molecular Structure of the Nanoscale Surface in Bionanoparticles. J. Am. Chem. Soc. 2017, 139, 111-114.

(138) Juweid, M.; Neumann, R.; Paik, C.; Perez-Bacete, M. J.; Sato, J.; van Osdol, W.; Weinstein, J. N. Micropharmacology of Monoclonal Antibodies in Solid Tumors: Direct Experimental Evidence for a Binding Site Barrier. Cancer Res. 1992, 52, 5144-5153.

(139) Schmidt, M. M.; Wittrup, K. D. A Modeling Analysis of the Effects of Molecular Size and Binding Affinity on Tumor Targeting. Mol. Cancer Ther. 2009, 8, 2861-2871. 
(140) Lee, H.; Fonge, H.; Hoang, B.; Reilly, R. M.; Allen, C. The Effects of Particle Size and Molecular Targeting on the Intratumoral and Subcellular Distribution of Polymeric Nanoparticles. Mol. Pharm. 2010, 7, 1195-1208.

(141) Miao, L.; Newby, J. M.; Lin, C. M.; Zhang, L.; Xu, F.; Kim, W. Y.; Forest, M. G.; Lai, S. K.; Milowsky, M. I.; Wobker, S. E.; Huang, L. The Binding Site Barrier Elicited by TumorAssociated Fibroblasts Interferes Disposition of Nanoparticles in Stroma-Vessel Type Tumors. ACS Nano 2016, 10, 9243-9258.

(142) Nichols, J. W.; Bae, Y. H. Odyssey of a Cancer Nanoparticle: From Injection Site to Site of Action. Nano Today 2012, 7, 606-618.

(143) Yan, Y.; Björnmalm, M.; Caruso, F. Assembly of Layer-by-Layer Particles and Their Interactions with Biological Systems. Chem. Mater. 2014, 26, 452-460.

(144) Blanco, E.; Shen, H.; Ferrari, M. Principles of Nanoparticle Design for Overcoming Biological Barriers to Drug Delivery. Nat. Biotechnol. 2015, 33, 941-951.

(145) Cheng, C. J.; Tietjen, G. T.; Saucier-Sawyer, J. K.; Saltzman, W. M. A Holistic Approach to Targeting Disease with Polymeric Nanoparticles. Nat. Rev. Drug Discov. 2015, 14, 239-247.

(146) Dawidczyk, C. M.; Russell, L. M.; Hultz, M.; Searson, P. C. Tumor Accumulation of Liposomal Doxorubicin in Three Murine Models: Optimizing Delivery Efficiency. Nanomed. Nanotechnol. Biol. Med. 2017, 13, 1637-1644.

(147) Song, G.; Suzuki, O. T.; Santos, C. M.; Lucas, A. T.; Wiltshire, T.; Zamboni, W. C. Gulp1 Is Associated with the Pharmacokinetics of PEGylated Liposomal Doxorubicin (PLD) in Inbred Mouse Strains. Nanomed. Nanotechnol. Biol. Med. 2016, 12, 2007-2017.

(148) Van Noorden, R. Scientists Still Fail to Record Age and Sex of Lab Mice. Nature 2016, in press. DOI: 10.1038 /nature.2016.19500.

(149) Florez-Vargas, O.; Brass, A.; Karystianis, G.; Bramhall, M.; Stevens, R.; Cruickshank, S.; Nenadic, G. Bias in the Reporting of Sex and Age in Biomedical Research on Mouse Models. eLife 2016, 5, e13615.

(150) Ekdawi, S. N.; Stewart, J. M. P.; Dunne, M.; Stapleton, S.; Mitsakakis, N.; Dou, Y. N.; Jaffray, D. A.; Allen, C. Spatial and Temporal Mapping of Heterogeneity in Liposome Uptake and Microvascular Distribution in an Orthotopic Tumor Xenograft Model. J. Controlled Release 2015, 207, 101-111.

(151) Zuckerman, J. E.; Gritli, I.; Tolcher, A.; Heidel, J. D.; Lim, D.; Morgan, R.; Chmielowski, B.; Ribas, A.; Davis, M. E.; Yen, Y. Correlating Animal and Human Phase Ia/Ib Clinical Data with CALAA-01, a Targeted, Polymer-Based Nanoparticle Containing siRNA. Proc. Natl. Acad. Sci. U. S. A. 2014, 111, 11449-11454.

(152) Eliasof, S.; Lazarus, D.; Peters, C. G.; Case, R. I.; Cole, R. O.; Hwang, J.; Schluep, T.; Chao, J.; Lin, J.; Yen, Y.; Han, H.; Wiley, D. T.; Zuckerman, J. E.; Davis, M. E. Correlating Preclinical Animal Studies and Human Clinical Trials of a Multifunctional, Polymeric Nanoparticle. Proc. Natl. Acad. Sci. U. S. A. 2013, 110, 15127-15132.

(153) Agoram, B. M.; Martin, S. W.; van der Graaf, P. H. The Role of Mechanism-Based Pharmacokinetic-pharmacodynamic (PK-PD) Modelling in Translational Research of Biologics. Drug Discov. Today 2007, 12, 1018-1024.

(154) Haddish-Berhane, N.; Shah, D. K.; Ma, D.; Leal, M.; Gerber, H.-P.; Sapra, P.; Barton, H. A.; 
Betts, A. M. On Translation of Antibody Drug Conjugates Efficacy from Mouse Experimental Tumors to the Clinic: A PK/PD Approach. J. Pharmacokinet. Pharmacodyn. 2013, 40, 557-571.

(155) Morgan, R. A. Human Tumor Xenografts: The Good, the Bad, and the Ugly. Mol. Ther. 2012, 20, 882-884.

(156) van der Worp, H. B.; Howells, D. W.; Sena, E. S.; Porritt, M. J.; Rewell, S.; O’Collins, V.; Macleod, M. R. Can Animal Models of Disease Reliably Inform Human Studies? PLOS Med. 2010, 7, e1000245.

(157) Mak, I. W.; Evaniew, N.; Ghert, M. Lost in Translation: Animal Models and Clinical Trials in Cancer Treatment. Am. J. Transl. Res. 2014, 6, 114-118.

(158) Park, K. Translation from Mouse to Human: Time to Think in New Boxes. J. Controlled Release 2014, 189, 187.

(159) Mitragotri, S.; Lammers, T.; Bae, Y. H.; Schwendeman, S.; De Smedt, S.; Leroux, J.-C.; Peer, D.; Kwon, I. C.; Harashima, H.; Kikuchi, A.; Oh, Y.-K.; Torchilin, V.; Hennink, W.; Hanes, J.; Park, K. Drug Delivery Research for the Future: Expanding the Nano Horizons and Beyond. J. Controlled Release 2017, 246, 183-184.

(160) Kummar, S.; Rubinstein, L.; Kinders, R.; Parchment, R. E.; Gutierrez, M. E.; Murgo, A. J.; Ji, J.; Mroczkowski, B.; Pickeral, O. K.; Simpson, M.; Hollingshead, M.; Yang, S. X.; Helman, L.; Wiltrout, R.; Collins, J.; Tomaszewski, J. E.; Doroshow, J. H. Phase 0 Clinical Trials: Conceptions and Misconceptions. Cancer J. 2008, 14, 133-137.

(161) Anselmo, A. C.; Prabhakarpandian, B.; Pant, K.; Mitragotri, S. Clinical and Commercial Translation of Advanced Polymeric Nanoparticle Systems: Opportunities and Material Challenges. Transl. Mater. Res. 2017, 4, 14001.

(162) Landesman-Milo, D.; Peer, D. Transforming Nanomedicines From Lab Scale Production to Novel Clinical Modality. Bioconjugate Chem. 2016, 27, 855-862.

(163) Agrahari, V.; Hiremath, P. Challenges Associated and Approaches for Successful Translation of Nanomedicines into Commercial Products. Nanomedicine 2017, 12, 819-823.

(164) Peng, W.; Unutmaz, D.; Ozbolat, I. T. Bioprinting towards Physiologically Relevant Tissue Models for Pharmaceutics. Trends Biotechnol. 2016, 34, 722-732.

(165) Gu, L.; Mooney, D. J. Biomaterials and Emerging Anticancer Therapeutics: Engineering the Microenvironment. Nat. Rev. Cancer 2015, 16, 56-66.

(166) Esch, E. W.; Bahinski, A.; Huh, D. Organs-on-Chips at the Frontiers of Drug Discovery. Nat. Rev. Drug Discov. 2015, 14, 248-260.

(167) Björnmalm, M.; Yan, Y.; Caruso, F. Engineering and Evaluating Drug Delivery Particles in Microfluidic Devices. J. Controlled Release 2014, 190, 139-149.

(168) Ozcelikkale, A.; Moon, H.; Linnes, M.; Han, B. In Vitro Microfluidic Models of Tumor Microenvironment to Screen Transport of Drugs and Nanoparticles. Wiley Interdiscip. Rev. Nanomed. Nanobiotechnol. 2017, e1460.

(169) Lazzari, G.; Couvreur, P.; Mura, S. Multicellular Tumor Spheroids: A Relevant 3D Model for the In Vitro Preclinical Investigation of Polymer Nanomedicines. Polym. Chem. 2017, in press. DOI: 10.1039/C7PY00559H.

(170) Priwitaningrum, D. L.; Blondé, J.-B. G.; Sridhar, A.; van Baarlen, J.; Hennink, W. E.; Storm, G.; 
Le Gac, S.; Prakash, J. Tumor Stroma-Containing 3D Spheroid Arrays: A Tool to Study Nanoparticle Penetration. J. Controlled Release 2016, 244, 257-268.

(171) Dienstmann, R.; Tabernero, J. Cancer: A Precision Approach to Tumour Treatment. Nature 2017, in press. DOI: $10.1038 /$ nature23101.

(172) Pauli, C.; Hopkins, B. D.; Prandi, D.; Shaw, R.; Fedrizzi, T.; Sboner, A.; Sailer, V.; Augello, M.; Puca, L.; Rosati, R.; McNary, T. J.; Churakova, Y.; Cheung, C.; Triscott, J.; Pisapia, D.; Rao, R.; Mosquera, J. M.; Robinson, B.; Faltas, B. M.; Emerling, B. E.; et al. Personalized In Vitro and In Vivo Cancer Models to Guide Precision Medicine. Cancer Discov. 2017, 7, 462-477.

(173) van den Brand, D.; Massuger, L. F.; Brock, R.; Verdurmen, W. P. R. Mimicking Tumors: Toward More Predictive In Vitro Models for Peptide- and Protein-Conjugated Drugs. Bioconjugate Chem. 2017, 28, 846-856.

(174) Schütte, M.; Risch, T.; Abdavi-Azar, N.; Boehnke, K.; Schumacher, D.; Keil, M.; Yildiriman, R.; Jandrasits, C.; Borodina, T.; Amstislavskiy, V.; Worth, C. L.; Schweiger, C.; Liebs, S.; Lange, M.; Warnatz, H.-J.; Butcher, L. M.; Barrett, J. E.; Sultan, M.; Wierling, C.; Golob-Schwarzl, N.; et al. Molecular Dissection of Colorectal Cancer in Pre-Clinical Models Identifies Biomarkers Predicting Sensitivity to EGFR Inhibitors. Nat. Commun. 2017, 8, 14262.

(175) Francia, G.; Cruz-Munoz, W.; Man, S.; Xu, P.; Kerbel, R. S. Mouse Models of Advanced Spontaneous Metastasis for Experimental Therapeutics. Nat. Rev. Cancer 2011, 11, 135-141.

(176) De Souza, R.; Spence, T.; Huang, H.; Allen, C. Preclinical Imaging and Translational Animal Models of Cancer for Accelerated Clinical Implementation of Nanotechnologies and Macromolecular Agents. J. Controlled Release 2015, 219, 313-330.

(177) Liu, J.; Blake, S. J.; Smyth, M. J.; Teng, M. W. Improved Mouse Models to Assess Tumour Immunity and irAEs after Combination Cancer Immunotherapies. Clin. Transl. Immunol. 2014, 3, e22.

(178) Paoloni, M.; Khanna, C. Translation of New Cancer Treatments from Pet Dogs to Humans. Nat. Rev. Cancer 2008, 8, 147-156.

(179) Dawidczyk, C. M.; Russell, L. M.; Searson, P. C. Nanomedicines for Cancer Therapy: State-ofthe-Art and Limitations to Pre-Clinical Studies That Hinder Future Developments. Front. Chem. 2014, 2, 69 .

(180) Harrington, K. J.; Rowlinson-Busza, G.; Syrigos, K. N.; Abra, R. M.; Uster, P. S.; Peters, A. M.; Stewart, J. S. W. Influence of Tumour Size on Uptake of1 11In-DTPA-Labelled Pegylated Liposomes in a Human Tumour Xenograft Model. Br. J. Cancer 2000, 83, 684-688.

(181) Mulvaney, P.; Parak, W. J.; Caruso, F.; Weiss, P. S. Standardizing Nanomaterials. ACS Nano 2016, 10, 9763-9764.

(182) Buriak, J. M.; Jones, C. W.; Kamat, P. V.; Schanze, K. S.; Schatz, G. C.; Scholes, G. D.; Weiss, P. S. Virtual Issue on Best Practices for Reporting the Properties of Materials and Devices. Chem. Mater. 2016, 28, 3525-3526.

(183) Nosek, B. A.; Alter, G.; Banks, G. C.; Borsboom, D.; Bowman, S. D.; Breckler, S. J.; Buck, S.; Chambers, C. D.; Chin, G.; Christensen, G.; Contestabile, M.; Dafoe, A.; Eich, E.; Freese, J.; Glennerster, R.; Goroff, D.; Green, D. P.; Hesse, B.; Humphreys, M.; Ishiyama, J.; et al. Promoting an Open Research Culture. Science 2015, 348, 1422-1425.

(184) Editorial. Transparency Upgrade for Nature Journals. Nature 2017, 543, 288-288. 
(185) Dawidczyk, C. M.; Russell, L. M.; Searson, P. C. Recommendations for Benchmarking Preclinical Studies of Nanomedicines. Cancer Res. 2015, 75, 4016-4020.

(186) Hare, J. I.; Lammers, T.; Ashford, M. B.; Puri, S.; Storm, G.; Barry, S. T. Challenges and Strategies in Anti-Cancer Nanomedicine Development: An Industry Perspective. Adv. Drug Deliv. Rev. 2017, 108, 25-38.

(187) Sun, Q.; Zhou, Z.; Qiu, N.; Shen, Y. Rational Design of Cancer Nanomedicine: Nanoproperty Integration and Synchronization. Adv. Mater. 2017, 29, 1606628.

(188) Raemdonck, K.; De Smedt, S. C. Lessons in Simplicity That Should Shape the Future of Drug Delivery. Nat. Biotechnol. 2015, 33, 1026-1027.

(189) Tian, X.; Lind, K. R.; Yuan, B.; Shaw, S.; Siemianowski, O.; Cademartiri, L. Simplicity as a Route to Impact in Materials Research. Adv. Mater. 2017, 29, 1604681.

(190) Anchordoquy, T. J.; Simberg, D. Watching the Gorilla and Questioning Delivery Dogma. $J$. Controlled Release 2017, 262, 87-90.

(191) MacEwan, S. R.; Chilkoti, A. From Composition to Cure: A Systems Engineering Approach to Anticancer Drug Carriers. Angew. Chem., Int. Ed. 2017, 56, 6712-6733.

(192) Khalil, D. N.; Smith, E. L.; Brentjens, R. J.; Wolchok, J. D. The Future of Cancer Treatment: Immunomodulation, CARs and Combination Immunotherapy. Nat. Rev. Clin. Oncol. 2016, 13, 273-290.

(193) Sadelain, M.; Rivière, I.; Riddell, S. Therapeutic T Cell Engineering. Nature 2017, 545, 423-431.

(194) Colby, A. H.; Berry, S. M.; Moran, A. M.; Pasion, K. A.; Liu, R.; Colson, Y. L.; Ruiz-Opazo, N.; Grinstaff, M. W.; Herrera, V. L. M. Highly Specific and Sensitive Fluorescent Nanoprobes for Image-Guided Resection of Sub-Millimeter Peritoneal Tumors. ACS Nano 2017, 11, 1466-1477.

(195) Kunz-Schughart, L. A.; Dubrovska, A.; Peitzsch, C.; Ewe, A.; Aigner, A.; Schellenburg, S.; Muders, M. H.; Hampel, S.; Cirillo, G.; Iemma, F.; Tietze, R.; Alexiou, C.; Stephan, H.; Zarschler, K.; Vittorio, O.; Kavallaris, M.; Parak, W. J.; Mädler, L.; Pokhrel, S. Nanoparticles for Radiooncology: Mission, Vision, Challenges. Biomaterials 2017, 120, 155-184.

(196) Goel, S.; Ni, D.; Cai, W. Harnessing the Power of Nanotechnology for Enhanced Radiation Therapy. ACS Nano 2017, 11, 5233-5237.

(197) Dai, W.; Wang, X.; Song, G.; Liu, T.; He, B.; Zhang, H.; Wang, X.; Zhang, Q. Combination Antitumor Therapy with Targeted Dual-Nanomedicines. Adv. Drug Deliv. Rev. 2017, in press. DOI: $10.1016 /$ j.addr.2017.03.001.

(198) Yan, Y.; Björnmalm, M.; Caruso, F. Particle Carriers for Combating Multidrug-Resistant Cancer. ACS Nano 2013, 7, 9512-9517.

(199) Smyth, M. J.; Ngiow, S. F.; Ribas, A.; Teng, M. W. L. Combination Cancer Immunotherapies Tailored to the Tumour Microenvironment. Nat. Rev. Clin. Oncol. 2015, 13, 143-158.

(200) Jiang, W.; Yuan, H.; Chan, C. K.; von Roemeling, C. A.; Yan, Z.; Weissman, I. L.; Kim, B. Y. S. Lessons from Immuno-Oncology: A New Era for Cancer Nanomedicine? Nat. Rev. Drug Discov. 2017, 16, 369-370.

(201) Kunjachan, S.; Ehling, J.; Storm, G.; Kiessling, F.; Lammers, T. Noninvasive Imaging of Nanomedicines and Nanotheranostics: Principles, Progress, and Prospects. Chem. Rev. 2015, 115, 10907-10937. 
(202) Spence, T.; De Souza, R.; Dou, Y.; Stapleton, S.; Reilly, R. M.; Allen, C. Integration of Imaging into Clinical Practice to Assess the Delivery and Performance of Macromolecular and Nanotechnology-Based Oncology Therapies. J. Controlled Release 2015, 219, 295-312.

(203) Yaari, Z.; da Silva, D.; Zinger, A.; Goldman, E.; Kajal, A.; Tshuva, R.; Barak, E.; Dahan, N.; Hershkovitz, D.; Goldfeder, M.; Roitman, J. S.; Schroeder, A. Theranostic Barcoded Nanoparticles for Personalized Cancer Medicine. Nat. Commun. 2016, 7, 13325.

(204) Mestel, R. Cancer: Imaging with Antibodies. Nature 2017, 543, 743-746.

(205) de Vries, E. G. E.; de Jong, S.; Gietema, J. A. Molecular Imaging As a Tool for Drug Development and Trial Design. J. Clin. Oncol. 2015, 33, 2585-2587.

(206) Ciprotti, M.; Tebbutt, N. C.; Lee, F.-T.; Lee, S.-T.; Gan, H. K.; McKee, D. C.; O’Keefe, G. J.; Gong, S. J.; Chong, G.; Hopkins, W.; Chappell, B.; Scott, F. E.; Brechbiel, M. W.; Tse, A. N.; Jansen, M.; Matsumura, M.; Kotsuma, M.; Watanabe, R.; Venhaus, R.; Beckman, R. A.; et al. Phase I Imaging and Pharmacodynamic Trial of CS-1008 in Patients With Metastatic Colorectal Cancer. J. Clin. Oncol. 2015, 33, 2609-2616.

(207) Smith, B. R.; Gambhir, S. S. Nanomaterials for In Vivo Imaging. Chem. Rev. 2017, 117, 901-986.

(208) Dearling, J. L. J.; Packard, A. B. Molecular Imaging in Nanomedicine - A Developmental Tool and a Clinical Necessity. J. Controlled Release 2017, 261, 23-30.

(209) Cheng, Z.; Al Zaki, A.; Hui, J. Z.; Muzykantov, V. R.; Tsourkas, A. Multifunctional Nanoparticles: Cost versus Benefit of Adding Targeting and Imaging Capabilities. Science 2012, 338, 903-910.

(210) Miller, M. A.; Gadde, S.; Pfirschke, C.; Engblom, C.; Sprachman, M. M.; Kohler, R. H.; Yang, K. S.; Laughney, A. M.; Wojtkiewicz, G.; Kamaly, N.; Bhonagiri, S.; Pittet, M. J.; Farokhzad, O. C.; Weissleder, R. Predicting Therapeutic Nanomedicine Efficacy Using a Companion Magnetic Resonance Imaging Nanoparticle. Sci. Transl. Med. 2015, 7, 314ra183.

(211) Manshian, B. B.; Jiménez, J.; Himmelreich, U.; Soenen, S. J. Personalized Medicine and Followup of Therapeutic Delivery through Exploitation of Quantum Dot Toxicity. Biomaterials 2017, $127,1-12$.

(212) Mohan, P.; Rapoport, N. Doxorubicin as a Molecular Nanotheranostic Agent: Effect of Doxorubicin Encapsulation in Micelles or Nanoemulsions on the Ultrasound-Mediated Intracellular Delivery and Nuclear Trafficking. Mol. Pharm. 2010, 7, 1959-1973.

(213) Björnmalm, M.; Roozmand, A.; Noi, K. F.; Guo, J.; Cui, J.; Richardson, J. J.; Caruso, F. FlowBased Assembly of Layer-by-Layer Capsules through Tangential Flow Filtration. Langmuir 2015, 31, 9054-9060.

(214) Lim, E.-K.; Kim, T.; Paik, S.; Haam, S.; Huh, Y.-M.; Lee, K. Nanomaterials for Theranostics: Recent Advances and Future Challenges. Chem. Rev. 2015, 115, 327-394.

(215) Arranja, A. G.; Pathak, V.; Lammers, T.; Shi, Y. Tumor-Targeted Nanomedicines for Cancer Theranostics. Pharmacol. Res. 2017, 115, 87-95.

(216) Chen, H.; Zhang, W.; Zhu, G.; Xie, J.; Chen, X. Rethinking Cancer Nanotheranostics. Nat. Rev. Mater. 2017, 2, 17024.

(217) Yu, M.; Zheng, J. Clearance Pathways and Tumor Targeting of Imaging Nanoparticles. ACS Nano 2015, 9, 6655-6674. 
(218) Yu, M.; Zhou, C.; Liu, L.; Zhang, S.; Sun, S.; Hankins, J. D.; Sun, X.; Zheng, J. Interactions of Renal-Clearable Gold Nanoparticles with Tumor Microenvironments: Vasculature and Acidity Effects. Angew. Chem., Int. Ed. 2017, 56, 4314-4319.

(219) Phillips, E.; Penate-Medina, O.; Zanzonico, P. B.; Carvajal, R. D.; Mohan, P.; Ye, Y.; Humm, J.; Gonen, M.; Kalaigian, H.; Schoder, H.; Strauss, H. W.; Larson, S. M.; Wiesner, U.; Bradbury, M. S. Clinical Translation of an Ultrasmall Inorganic Optical-PET Imaging Nanoparticle Probe. Sci. Transl. Med. 2014, 6, 260ra149.

(220) Primeau, A. J.; Rendon, A.; Hedley, D.; Lilge, L.; Tannock, I. F. The Distribution of the Anticancer Drug Doxorubicin in Relation to Blood Vessels in Solid Tumors. Clin. Cancer Res. 2005, 11, 8782-8788.

(221) Huang, K.; Ma, H.; Liu, J.; Huo, S.; Kumar, A.; Wei, T.; Zhang, X.; Jin, S.; Gan, Y.; Wang, P. C.; He, S.; Zhang, X.; Liang, X.-J. Size-Dependent Localization and Penetration of Ultrasmall Gold Nanoparticles in Cancer Cells, Multicellular Spheroids, and Tumors In Vivo. ACS Nano 2012, 6, 4483-4493.

(222) Albanese, A.; Lam, A. K.; Sykes, E. A.; Rocheleau, J. V.; Chan, W. C. W. Tumour-on-a-Chip Provides an Optical Window into Nanoparticle Tissue Transport. Nat. Commun. 2013, 4, 2718.

(223) Agarwal, R.; Jurney, P.; Raythatha, M.; Singh, V.; Sreenivasan, S. V.; Shi, L.; Roy, K. Effect of Shape, Size, and Aspect Ratio on Nanoparticle Penetration and Distribution inside Solid Tissues Using 3D Spheroid Models. Adv. Healthcare Mater. 2015, 4, 2269-2280.

(224) Braunger, J. A.; Björnmalm, M.; Isles, N. A.; Cui, J.; Henderson, T. M. A.; O’Connor, A. J.; Caruso, F. Interactions between Circulating Nanoengineered Polymer Particles and Extracellular Matrix Components In Vitro. Biomater. Sci. 2017, 5, 267-273.

(225) Sykes, E. A.; Dai, Q.; Sarsons, C. D.; Chen, J.; Rocheleau, J. V.; Hwang, D. M.; Zheng, G.; Cramb, D. T.; Rinker, K. D.; Chan, W. C. W. Tailoring Nanoparticle Designs to Target Cancer Based on Tumor Pathophysiology. Proc. Natl. Acad. Sci. U. S. A. 2016, 113, E1142-E1151.

(226) Ruoslahti, E. Tumor Penetrating Peptides for Improved Drug Delivery. Adv. Drug Deliv. Rev. 2017, 110-111, 3-12.

(227) Sugahara, K. N.; Teesalu, T.; Karmali, P. P.; Kotamraju, V. R.; Agemy, L.; Girard, O. M.; Hanahan, D.; Mattrey, R. F.; Ruoslahti, E. Tissue-Penetrating Delivery of Compounds and Nanoparticles into Tumors. Cancer Cell 2009, 16, 510-520.

(228) Sugahara, K. N.; Teesalu, T.; Karmali, P. P.; Kotamraju, V. R.; Agemy, L.; Greenwald, D. R.; Ruoslahti, E. Coadministration of a Tumor-Penetrating Peptide Enhances the Efficacy of Cancer Drugs. Science 2010, 328, 1031-1035.

(229) Wang, Y.; Xie, Y.; Li, J.; Peng, Z.-H.; Sheinin, Y.; Zhou, J.; Oupický, D. Tumor-Penetrating Nanoparticles for Enhanced Anticancer Activity of Combined Photodynamic and HypoxiaActivated Therapy. ACS Nano 2017, 11, 2227-2238.

(230) Sun, Q.; Ojha, T.; Kiessling, F.; Lammers, T.; Shi, Y. Enhancing Tumor Penetration of Nanomedicines. Biomacromolecules 2017, 18, 1449-1459.

(231) Adiseshaiah, P. P.; Crist, R. M.; Hook, S. S.; McNeil, S. E. Nanomedicine Strategies to Overcome the Pathophysiological Barriers of Pancreatic Cancer. Nat. Rev. Clin. Oncol. 2016, 13, 750-765.

(232) Dai, Y.; Xu, C.; Sun, X.; Chen, X. Nanoparticle Design Strategies for Enhanced Anticancer Therapy by Exploiting the Tumour Microenvironment. Chem. Soc. Rev. 2017, 46, 3830-3852. 
(233) Miller, M. A.; Zheng, Y.-R.; Gadde, S.; Pfirschke, C.; Zope, H.; Engblom, C.; Kohler, R. H.; Iwamoto, Y.; Yang, K. S.; Askevold, B.; Kolishetti, N.; Pittet, M.; Lippard, S. J.; Farokhzad, O. C.; Weissleder, R. Tumour-Associated Macrophages Act as a Slow-Release Reservoir of NanoTherapeutic Pt(IV) pro-Drug. Nat. Commun. 2015, 6, 8692.

(234) Tanei, T.; Leonard, F.; Liu, X.; Alexander, J. F.; Saito, Y.; Ferrari, M.; Godin, B.; Yokoi, K. Redirecting Transport of Nanoparticle Albumin-Bound Paclitaxel to Macrophages Enhances Therapeutic Efficacy against Liver Metastases. Cancer Res. 2016, 76, 429-439.

(235) Singh, Y.; Pawar, V. K.; Meher, J. G.; Raval, K.; Kumar, A.; Shrivastava, R.; Bhadauria, S.; Chourasia, M. K. Targeting Tumor Associated Macrophages (TAMs) via Nanocarriers. J. Controlled Release 2017, 254, 92-106.

(236) Leonard, F.; Curtis, L. T.; Yesantharao, P.; Tanei, T.; Alexander, J. F.; Wu, M.; Lowengrub, J.; Liu, X.; Ferrari, M.; Yokoi, K.; Frieboes, H. B.; Godin, B. Enhanced Performance of MacrophageEncapsulated Nanoparticle Albumin-Bound-Paclitaxel in Hypo-Perfused Cancer Lesions. Nanoscale 2016, 8, 12544-12552.

(237) Xue, J.; Zhao, Z.; Zhang, L.; Xue, L.; Shen, S.; Wen, Y.; Wei, Z.; Wang, L.; Kong, L.; Sun, H.; Ping, Q.; Mo, R.; Zhang, C. Neutrophil-Mediated Anticancer Drug Delivery for Suppression of Postoperative Malignant Glioma Recurrence. Nat. Nanotechnol. 2017, 12, 692-700.

(238) Hu, Q.; Sun, W.; Lu, Y.; Bomba, H. N.; Ye, Y.; Jiang, T.; Isaacson, A. J.; Gu, Z. Tumor Microenvironment-Mediated Construction and Deconstruction of Extracellular Drug-Delivery Depots. Nano Lett. 2016, 16, 1118-1126.

(239) Miller, M. A.; Chandra, R.; Cuccarese, M. F.; Pfirschke, C.; Engblom, C.; Stapleton, S.; Adhikary, U.; Kohler, R. H.; Mohan, J. F.; Pittet, M. J.; Weissleder, R. Radiation Therapy Primes Tumors for Nanotherapeutic Delivery via Macrophage-Mediated Vascular Bursts. Sci. Transl. Med. 2017, 9, eaal0225.

(240) Godin, B.; Tasciotti, E.; Liu, X.; Serda, R. E.; Ferrari, M. Multistage Nanovectors: From Concept to Novel Imaging Contrast Agents and Therapeutics. Acc. Chem. Res. 2011, 44, 979-989.

(241) Patra, M.; Zarschler, K.; Pietzsch, H.-J.; Stephan, H.; Gasser, G. New Insights into the Pretargeting Approach to Image and Treat Tumours. Chem. Soc. Rev. 2016, 45, 6415-6431.

(242) Emmetiere, F.; Irwin, C.; Viola-Villegas, N. T.; Longo, V.; Cheal, S. M.; Zanzonico, P.; Pillarsetty, N.; Weber, W. A.; Lewis, J. S.; Reiner, T. 18 F-Labeled-Bioorthogonal Liposomes for In Vivo Targeting. Bioconjugate Chem. 2013, 24, 1784-1789.

(243) Wong, C.; Stylianopoulos, T.; Cui, J.; Martin, J.; Chauhan, V. P.; Jiang, W.; Popovic, Z.; Jain, R. K.; Bawendi, M. G.; Fukumura, D. Multistage Nanoparticle Delivery System for Deep Penetration into Tumor Tissue. Proc. Natl. Acad. Sci. U. S. A. 2011, 108, 2426-2431.

(244) Xu, R.; Zhang, G.; Mai, J.; Deng, X.; Segura-Ibarra, V.; Wu, S.; Shen, J.; Liu, H.; Hu, Z.; Chen, L.; Huang, Y.; Koay, E.; Huang, Y.; Liu, J.; Ensor, J. E.; Blanco, E.; Liu, X.; Ferrari, M.; Shen, H. An Injectable Nanoparticle Generator Enhances Delivery of Cancer Therapeutics. Nat. Biotechnol. 2016, 34, 414-418.

(245) Li, H.-J.; Du, J.-Z.; Du, X.-J.; Xu, C.-F.; Sun, C.-Y.; Wang, H.-X.; Cao, Z.-T.; Yang, X.-Z.; Zhu, Y.-H.; Nie, S.; Wang, J. Stimuli-Responsive Clustered Nanoparticles for Improved Tumor Penetration and Therapeutic Efficacy. Proc. Natl. Acad. Sci. U. S. A. 2016, 113, 4164-4169.

(246) Della Rocca, J.; Liu, D.; Lin, W. Are High Drug Loading Nanoparticles the Next Step Forward for Chemotherapy? Nanomedicine 2012, 7, 303-305. 
(247) Schumacher, T. N.; Schreiber, R. D. Neoantigens in Cancer Immunotherapy. Science 2015, 348, 69-74.

(248) Joyce, J. A.; Fearon, D. T. T Cell Exclusion, Immune Privilege, and the Tumor Microenvironment. Science 2015, 348, 74-80.

(249) Pitt, J. M.; Marabelle, A.; Eggermont, A.; Soria, J.-C.; Kroemer, G.; Zitvogel, L. Targeting the Tumor Microenvironment: Removing Obstruction to Anticancer Immune Responses and Immunotherapy. Ann. Oncol. 2016, 27, 1482-1492.

(250) van der Burg, S. H.; Arens, R.; Ossendorp, F.; van Hall, T.; Melief, C. J. M. Vaccines for Established Cancer: Overcoming the Challenges Posed by Immune Evasion. Nat. Rev. Cancer 2016, 16, 219-233.

(251) Pardoll, D. M. The Blockade of Immune Checkpoints in Cancer Immunotherapy. Nat. Rev. Cancer 2012, 12, 252-264.

(252) Zou, W.; Wolchok, J. D.; Chen, L. PD-L1 (B7-H1) and PD-1 Pathway Blockade for Cancer Therapy: Mechanisms, Response Biomarkers, and Combinations. Sci. Transl. Med. 2016, 8, 328rv4.

(253) Sharma, P.; Allison, J. P. The Future of Immune Checkpoint Therapy. Science 2015, 348, 56-61.

(254) Bender, E. How Scientists Aim to Expand Immunotherapy Options for Cancer Patients http://blog.dana-farber.org/insight/2016/04/how-scientists-aim-to-expand-immunotherapy-optionsfor-cancer-patients/ (accessed Apr 15, 2017).

(255) Sharon, E. Can an Immune Checkpoint Inhibitor (Sometimes) Make Things Worse? Clin. Cancer Res. 2017, 23, 1879-1881.

(256) Naidoo, J.; Page, D. B.; Li, B. T.; Connell, L. C.; Schindler, K.; Lacouture, M. E.; Postow, M. A.; Wolchok, J. D. Toxicities of the Anti-PD-1 and Anti-PD-L1 Immune Checkpoint Antibodies. Ann. Oncol. 2015, 26, 2375-2391.

(257) Goldberg, M. S. Immunoengineering: How Nanotechnology Can Enhance Cancer Immunotherapy. Cell 2015, 161, 201-204.

(258) Irvine, D. J. Materializing the Future of Vaccines and Immunotherapy. Nat. Rev. Mater. 2016, 1, 15008.

(259) Smith, D. M.; Simon, J. K.; Baker, J. R. Applications of Nanotechnology for Immunology. Nat. Rev. Immunol. 2013, 13, 592-605.

(260) Gause, K. T.; Wheatley, A. K.; Cui, J.; Yan, Y.; Kent, S. J.; Caruso, F. Immunological Principles Guiding the Rational Design of Particles for Vaccine Delivery. ACS Nano 2017, 11, 54-68.

(261) Jiang, W.; von Roemeling, C. A.; Chen, Y.; Qie, Y.; Liu, X.; Chen, J.; Kim, B. Y. S. Designing Nanomedicine for Immuno-Oncology. Nat. Biomed. Eng. 2017, 1, 29.

(262) Kapadia, C. H.; Perry, J. L.; Tian, S.; Luft, J. C.; DeSimone, J. M. Nanoparticulate Immunotherapy for Cancer. J. Controlled Release 2015, 219, 167-180.

(263) Shao, K.; Singha, S.; Clemente-Casares, X.; Tsai, S.; Yang, Y.; Santamaria, P. Nanoparticle-Based Immunotherapy for Cancer. ACS Nano 2015, 9, 16-30.

(264) Qiu, H.; Min, Y.; Rodgers, Z.; Zhang, L.; Wang, A. Z. Nanomedicine Approaches to Improve Cancer Immunotherapy. Wiley Interdiscip. Rev. Nanomed. Nanobiotechnol. 2017, e1456. 
(265) Milling, L.; Zhang, Y.; Irvine, D. J. Delivering Safer Immunotherapies for Cancer. Adv. Drug Deliv. Rev. 2017, in press. DOI: 10.1016/j.addr.2017.05.011.

(266) Wang, C.; Ye, Y.; Hu, Q.; Bellotti, A.; Gu, Z. Tailoring Biomaterials for Cancer Immunotherapy: Emerging Trends and Future Outlook. Adv. Mater. 2017, in press. DOI: 10.1002/adma.201606036.

(267) Hume, D. A. The Mononuclear Phagocyte System. Curr. Opin. Immunol. 2006, 18, 49-53.

(268) De Koker, S.; Cui, J.; Vanparijs, N.; Albertazzi, L.; Grooten, J.; Caruso, F.; De Geest, B. G. Engineering Polymer Hydrogel Nanoparticles for Lymph Node-Targeted Delivery. Angew. Chem., Int. Ed. 2016, 55, 1334-1339.

(269) Yang, Y.-S. S.; Atukorale, P. U.; Moynihan, K. D.; Bekdemir, A.; Rakhra, K.; Tang, L.; Stellacci, F.; Irvine, D. J. High-Throughput Quantitation of Inorganic Nanoparticle Biodistribution at the Single-Cell Level Using Mass Cytometry. Nat. Commun. 2017, 8, 14069.

(270) Irvine, D. J.; Hanson, M. C.; Rakhra, K.; Tokatlian, T. Synthetic Nanoparticles for Vaccines and Immunotherapy. Chem. Rev. 2015, 115, 11109-11146.

(271) Ergen, C.; Heymann, F.; Al Rawashdeh, W.; Gremse, F.; Bartneck, M.; Panzer, U.; Pola, R.; Pechar, M.; Storm, G.; Mohr, N.; Barz, M.; Zentel, R.; Kiessling, F.; Trautwein, C.; Lammers, T.; Tacke, F. Targeting Distinct Myeloid Cell Populations In Vivo Using Polymers, Liposomes and Microbubbles. Biomaterials 2017, 114, 106-120.

(272) Tsoi, K. M.; MacParland, S. A.; Ma, X.-Z.; Spetzler, V. N.; Echeverri, J.; Ouyang, B.; Fadel, S. M.; Sykes, E. A.; Goldaracena, N.; Kaths, J. M.; Conneely, J. B.; Alman, B. A.; Selzner, M.; Ostrowski, M. A.; Adeyi, O. A.; Zilman, A.; McGilvray, I. D.; Chan, W. C. W. Mechanism of Hard-Nanomaterial Clearance by the Liver. Nat. Mater. 2016, 15, 1212-1221.

(273) MacParland, S. A.; Tsoi, K. M.; Ouyang, B.; Ma, X.-Z.; Manuel, J.; Fawaz, A.; Ostrowski, M. A.; Alman, B. A.; Zilman, A.; Chan, W. C. W.; McGilvray, I. D. Phenotype Determines Nanoparticle Uptake by Human Macrophages from Liver and Blood. ACS Nano 2017, 11, 2428-2443.

(274) Nguyen-Lefebvre, A. T.; Horuzsko, A. Kupffer Cell Metabolism and Function. Enzymol. Metab. J. 2015, $1,101$.

(275) Paschos, K. A.; Majeed, A. W.; Bird, N. C. Role of Kupffer Cells in the Outgrowth of Colorectal Cancer Liver Metastases. Hepatol. Res. 2010, 40, 83-94.

(276) Cho, N.-H.; Cheong, T.-C.; Min, J. H.; Wu, J. H.; Lee, S. J.; Kim, D.; Yang, J.-S.; Kim, S.; Kim, Y. K.; Seong, S.-Y. A Multifunctional Core-shell Nanoparticle for Dendritic Cell-Based Cancer Immunotherapy. Nat. Nanotechnol. 2011, 6, 675-682.

(277) Li, H.; Li, Y.; Jiao, J.; Hu, H.-M. Alpha-Alumina Nanoparticles Induce Efficient AutophagyDependent Cross-Presentation and Potent Antitumour Response. Nat. Nanotechnol. 2011, 6, 645650 .

(278) Palucka, K.; Banchereau, J. Cancer Immunotherapy via Dendritic Cells. Nat. Rev. Cancer 2012, 12, 265-277.

(279) Luo, M.; Wang, H.; Wang, Z.; Cai, H.; Lu, Z.; Li, Y.; Du, M.; Huang, G.; Wang, C.; Chen, X.; Porembka, M. R.; Lea, J.; Frankel, A. E.; Fu, Y.-X.; Chen, Z. J.; Gao, J. A STING-Activating Nanovaccine for Cancer Immunotherapy. Nat. Nanotechnol. 2017, 12, 648-654.

(280) Min, Y.; Roche, K. C.; Tian, S.; Eblan, M. J.; McKinnon, K. P.; Caster, J. M.; Chai, S.; Herring, L. E.; Zhang, L.; Zhang, T.; DeSimone, J. M.; Tepper, J. E.; Vincent, B. G.; Serody, J. S.; Wang, 
A. Z. Antigen-Capturing Nanoparticles Improve the Abscopal Effect and Cancer Immunotherapy. Nat. Nanotechnol. 2017, in press. DOI: 10.1038/nnano.2017.113.

(281) Kranz, L. M.; Diken, M.; Haas, H.; Kreiter, S.; Loquai, C.; Reuter, K. C.; Meng, M.; Fritz, D.; Vascotto, F.; Hefesha, H.; Grunwitz, C.; Vormehr, M.; Hüsemann, Y.; Selmi, A.; Kuhn, A. N.; Buck, J.; Derhovanessian, E.; Rae, R.; Attig, S.; Diekmann, J.; et al. Systemic RNA Delivery to Dendritic Cells Exploits Antiviral Defence for Cancer Immunotherapy. Nature 2016, 534, 396401.

(282) Smith, T. T.; Stephan, S. B.; Moffett, H. F.; McKnight, L. E.; Ji, W.; Reiman, D.; Bonagofski, E.; Wohlfahrt, M. E.; Pillai, S. P. S.; Stephan, M. T. In Situ Programming of Leukaemia-Specific T Cells Using Synthetic DNA Nanocarriers. Nat. Nanotechnol. 2017, in press. DOI: 10.1038/nnano.2017.57.

(283) Park, J.; Wrzesinski, S. H.; Stern, E.; Look, M.; Criscione, J.; Ragheb, R.; Jay, S. M.; Demento, S. L.; Agawu, A.; Licona Limon, P.; Ferrandino, A. F.; Gonzalez, D.; Habermann, A.; Flavell, R. A.; Fahmy, T. M. Combination Delivery of TGF- $\beta$ Inhibitor and IL-2 by Nanoscale Liposomal Polymeric Gels Enhances Tumour Immunotherapy. Nat. Mater. 2012, 11, 895-905.

(284) Lizotte, P. H.; Wen, A. M.; Sheen, M. R.; Fields, J.; Rojanasopondist, P.; Steinmetz, N. F.; Fiering, S. In Situ Vaccination with Cowpea Mosaic Virus Nanoparticles Suppresses Metastatic Cancer. Nat. Nanotechnol. 2016, 11, 295-303.

(285) Chen, Q.; Xu, L.; Liang, C.; Wang, C.; Peng, R.; Liu, Z. Photothermal Therapy with ImmuneAdjuvant Nanoparticles Together with Checkpoint Blockade for Effective Cancer Immunotherapy. Nat. Commun. 2016, 7, 13193.

(286) Mizrahy, S.; Hazan-Halevy, I.; Landesman-Milo, D.; Ng, B. D.; Peer, D. Advanced Strategies in Immune Modulation of Cancer Using Lipid-Based Nanoparticles. Front. Immunol. 2017, 8, 69.

(287) Lu, Y.; Wang, Y.; Miao, L.; Haynes, M.; Xiang, G.; Huang, L. Exploiting In Situ Antigen Generation and Immune Modulation to Enhance Chemotherapy Response in Advanced Melanoma: A Combination Nanomedicine Approach. Cancer Lett. 2016, 379, 32-38.

(288) Koshy, S. T.; Cheung, A. S.; Gu, L.; Graveline, A. R.; Mooney, D. J. Liposomal Delivery Enhances Immune Activation by STING Agonists for Cancer Immunotherapy. Adv. Biosyst. 2017, 1,1600013 .

(289) Ahmed, K. K.; Geary, S. M.; Salem, A. K. Surface Engineering Tumor Cells with AdjuvantLoaded Particles for Use as Cancer Vaccines. J. Controlled Release 2017, 248, 1-9.

(290) Zheng, Y.; Tang, L.; Mabardi, L.; Kumari, S.; Irvine, D. J. Enhancing Adoptive Cell Therapy of Cancer through Targeted Delivery of Small-Molecule Immunomodulators to Internalizing or Noninternalizing Receptors. ACS Nano 2017, 11, 3089-3100.

(291) Kosmides, A. K.; Sidhom, J.-W.; Fraser, A.; Bessell, C. A.; Schneck, J. P. Dual Targeting Nanoparticle Stimulates the Immune System To Inhibit Tumor Growth. ACS Nano 2017, 11, $5417-5429$.

(292) Moynihan, K. D.; Opel, C. F.; Szeto, G. L.; Tzeng, A.; Zhu, E. F.; Engreitz, J. M.; Williams, R. T.; Rakhra, K.; Zhang, M. H.; Rothschilds, A. M.; Kumari, S.; Kelly, R. L.; Kwan, B. H.; Abraham, W.; Hu, K.; Mehta, N. K.; Kauke, M. J.; Suh, H.; Cochran, J. R.; Lauffenburger, D. A.; et al. Eradication of Large Established Tumors in Mice by Combination Immunotherapy That Engages Innate and Adaptive Immune Responses. Nat. Med. 2016, 22, 1402-1410.

(293) Spitzer, M. H.; Carmi, Y.; Reticker-Flynn, N. E.; Kwek, S. S.; Madhireddy, D.; Martins, M. M.; 
Gherardini, P. F.; Prestwood, T. R.; Chabon, J.; Bendall, S. C.; Fong, L.; Nolan, G. P.; Engleman, E. G. Systemic Immunity Is Required for Effective Cancer Immunotherapy. Cell 2017, 168, 487502.

(294) Chan, W. C. W. Nanomedicine 2.0. Acc. Chem. Res. 2017, 50, 627-632.

(295) Whitesides, G. M. Reinventing Chemistry. Angew. Chem., Int. Ed. 2015, 54, 3196-3209.

(296) Weinberg, R. A. Coming Full Circle-From Endless Complexity to Simplicity and Back Again. Cell 2014, 157, 267-271.

(297) Munafò, M. R.; Nosek, B. A.; Bishop, D. V. M.; Button, K. S.; Chambers, C. D.; Percie du Sert, N.; Simonsohn, U.; Wagenmakers, E.-J.; Ware, J. J.; Ioannidis, J. P. A. A Manifesto for Reproducible Science. Nat. Hum. Behav. 2017, 1, 21. 
Table of Contents graphic

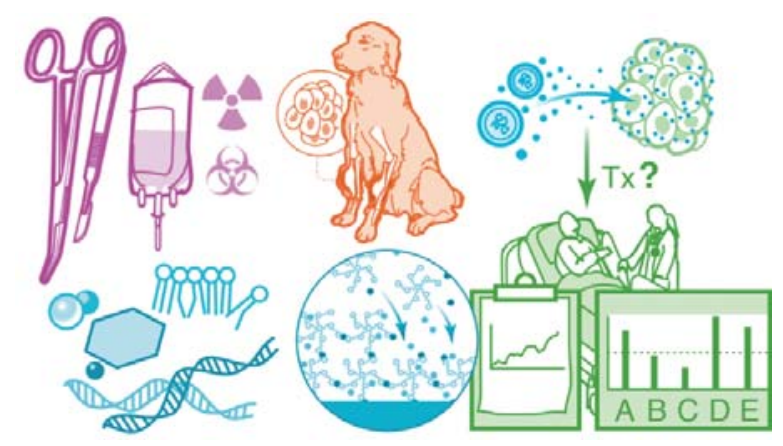

Keywords: nanomaterials, nanoparticles, nanoengineering, antibodies, comparative oncology, metastasis, heterogeneity, tumor targeting 